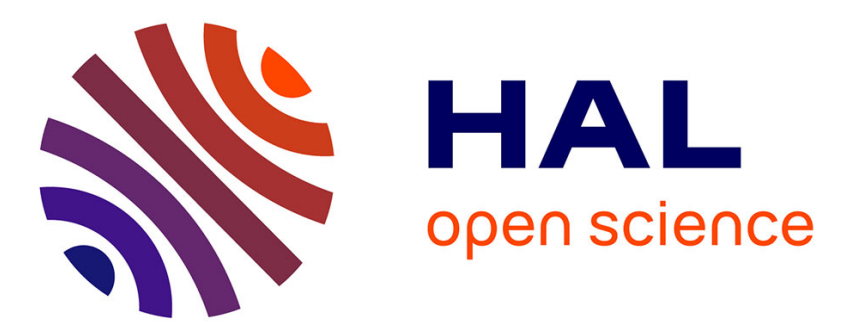

\title{
Predicting the surface tension of aqueous 1:1 electrolyte solutions at high salinity
}

\author{
Philippe Leroy, Arnault Lassin, Mohamed Azaroual, Laurent André
}

\section{To cite this version:}

Philippe Leroy, Arnault Lassin, Mohamed Azaroual, Laurent André. Predicting the surface tension of aqueous 1:1 electrolyte solutions at high salinity. Geochimica et Cosmochimica Acta, 2010, 74 (19), p. 5427-5442. 10.1016/j.gca.2010.06.012 . hal-00546916

\section{HAL Id: hal-00546916 https://hal-brgm.archives-ouvertes.fr/hal-00546916}

Submitted on 15 Dec 2010

HAL is a multi-disciplinary open access archive for the deposit and dissemination of scientific research documents, whether they are published or not. The documents may come from teaching and research institutions in France or abroad, or from public or private research centers.
L'archive ouverte pluridisciplinaire HAL, est destinée au dépôt et à la diffusion de documents scientifiques de niveau recherche, publiés ou non, émanant des établissements d'enseignement et de recherche français ou étrangers, des laboratoires publics ou privés. 


\section{Predicting the surface tension of aqueous 1-1 electrolyte solutions at high salinity}

Philippe Leroy ${ }^{\mathrm{a}^{*}}$, Arnault Lassin ${ }^{\mathrm{a}}$, Mohamed Azaroual ${ }^{\mathrm{a}}$, Laurent André ${ }^{\mathrm{a}}$

${ }^{\text {a }}$ BRGM, 3 avenue C. Guillemin, BP 6009, 45061 Orléans, France

${ }^{*}$ Corresponding author:

Philippe Leroy

BRGM

Water Division (EAU/M2H)

3 Avenue Claude Guillemin

45060 Orléans Cedex 2, France

E-mail: p.leroy@brgm.fr

Tel: +33 (0)2 38643973

Fax: +33 (0)2 38643719

Intended for publication in Geochimica et Cosmochimica Acta 


\begin{abstract}
The surface tension of the air/water interface is a phenomenon of particular interest in the water-unsaturated zone of porous media because it influences the contact angle and consequently the capillary water volume. A mechanistic model based on the modified Poisson-Boltzmann equation and the Pitzer theory is described and used to predict, under isothermal and isobaric conditions, the surface tension of 1:1 electrolytes at high salinity. These theories enable the determination of the electrical potential at the air/water interface and the activity coefficient of the ionic species in the bulk pore water, respectively. Hydration free energies of the structure-making and structure-breaking ions that influence the surface tension at high salinity are taken into account. Structure-making ions flee the air/water surface because they can better organize the water dipoles in bulk water than at the interface. Structure-breaking ions are positively adsorbed at the air/water interface because the bulk water can better organize their hydrogen bonding network without these ions. The resulting surface tension increases and decreases, respectively, compared to the surface tension of pure water. The model predictions are in good agreement with the surface tension data for 1:1 electrolytes ( $\mathrm{NaCl}, \mathrm{KCl}, \mathrm{HCl}, \mathrm{NaNO}_{3}, \mathrm{KNO}_{3}, \mathrm{HNO}_{3}$ electrolytes) and the optimized parameters depend on the effective electrostatic diameters of cations and on the hydration free energies of the ions at the interface.
\end{abstract}




\section{INTRODUCTION}

The surface tension of aqueous electrolyte solutions is an important physical and chemical property of the porous medium, particularly in the unsaturated zone (UZ), that retains aqueous solutions against gravity and evaporation by capillary forces. For example, unsaturated flow of water induced by hydraulic head gradients caused by concentrationdependent surface tension changes has been demonstrated in the laboratory (Smith and Gillham, 1999; Henry et al., 2001). These authors studied the transport properties of porous media contaminated with organic solutes that reduce the surface tension of water. The surface tension of the gas/water interface combined with the mineral/water and mineral/gas interfacial energies also enables the calculation of the contact angle (Douillard and Médout-Marère, 2000; Mercury et al., 2003; Ward and Sefiane, 2009). Environmental problems like salt weathering need to characterize the drying kinetics of porous media (Sghaier et al., 2006). In this context, crystallisation of salt in the pores are responsible for the deterioration of buildings materials. According to Prat (2007), pore shape and contact angle can greatly affect the drying kinetics. This author used pore network simulations to explore the influence of these geometrical and physico-chemical parameters on drying rates. Predicting the surface tension of the gas/water interface might also be of crucial importance in some industrial contexts. For example, capillary failure in the context of $\mathrm{CO}_{2}$ geological storage is, to a large extent, controlled by the gas/water surface tension. The higher the surface tension, the higher the pressure difference between the non-wetting (gas) and wetting (brine) phases is to attain capillary failure (André et al., 2007; Chiquet et al., 2007; Pettenati et al., 2008). Another application is the study of heterogeneous chemistry involving sea-salt aerosols, which influences the chemical composition of the atmosphere (Jungwirth and Tobias, 2001, 2006). 
The surface tensions of 1:1 aqueous electrolytes are usually higher than that of pure water. Any solute that increases the surface tension of water may exhibit a negative total adsorption at the air/water interface, according to the Gibbs adsorption equation (Weissenborn and Pugh, 1996). The depletion of such ions near the water's surface was long attributed to repulsive electrostatic image forces (Onsager and Samaras, 1934). Their theory was criticised, particularly at high salinity $(>0.2 \mathrm{M})$, for its oversimplification, mathematical treatment and neglect of water's structure. Recent molecular dynamics simulations have shown that the common belief that the interfacial region is depleted of ions might not be true (Jungwirth and Tobias, 2001, 2006). At high ionic strengths, the effect of ions on water's structure (structuremaking or structure-breaking ions) may be responsible for the variation of surface tension with salinity (Horne and Young, 1972; Ralston and Healy, 1973; Manciu and Ruckenstein, 2003, 2005). The effect of ion hydration on interfacial tension can be easily understood qualitatively. Structure-making ions flee the interface because they can better organize the water dipoles in bulk water than at the interface (Fig. 1). They orient the hydrogen of the water molecules of the solvation shell towards their neighbouring water molecules in the aqueous solution, with which they can create hydrogen bonds. The opposite is true for the structure-breaking ions. The total free energy of the system is minimized by pushing the structure-breaking ions toward the interface because the bulk water can better organize their hydrogen bonding network without these ions.

Some macroscopic models can explain the variation of the surface tension with the salinity of the solution. Yu et al. (2000) studied the ionic concentration dependence of the surface tension of single and mixed electrolyte solutions. They utilized the mean spherical approximation method ( $\mathrm{Lu}$ et al., 1993) to estimate the activity coefficients of water in the air/water interface and bulk liquid phase. For that purpose, they used the phenomenological surface-phase method (Guggenheim and Adam,1933) on the basis of Gibbs thermodynamic 
analysis. $\mathrm{Li}$ and $\mathrm{Lu}$ (2001) employed a combination of the Gibbs chemical potential concept and the Langmuir adsorption model (Desnoyer et al., 1997) to study the surface tension of single and mixed electrolyte solutions. The activity coefficients were calculated thanks to the Pitzer theory (Pitzer, 1973). However, Yu et al. (2000) and Li and Lu (2001) used some empirical parameters in the adsorption equilibrium constants that are not specific to the effect of ions on water's structure. Recently, continuum electrostatic models (in which the solvent is considered to be a continuum) have been developed based on the modified PoissonBoltzmann (MPB) approach (Bhuiyan et al., 1991; Bhuiyan et al., 1992; Karraker and Radke, 2002; Markin and Volkov, 2002; Manciu and Ruckenstein, 2003, 2005). These models consider ion-specific behaviour including, in some cases, a propensity of certain types of ions for the air/water interface. Bhuiyan et al. (1991) studied the surface tension of aqueous electrolytes within the framework of the primitive model of the planar electric double layer. The excess surface tension was determined by numerical integration of the Gibbs adsorption isotherm. The primitive model they used can describe very well the surface properties of the air/water interface. The MPB allows the determination of the singlet density profiles and the surface deficit of the ions repelled from the polarized interface. The bulk MPB equation was also used for the calculation of the activity coefficients in the bulk water. Karraker and Radke (2002) developed a self-consistent electrostatic theory to predict successfully disjoining pressure isotherms of aqueous thin-liquid films stabilized by non-ionic surfactants, air/water surface tensions and zeta potentials of single electrolyte solutions. Their theory is based on specific adsorption of hydroxide ions at the interface, and image plus dispersion forces due to Van der Waals interactions on ions. Markin and Volkov (2002), in their model, included image forces, ions of finite radii and the hydrophobic effect at liquid interfaces. Manciu and Ruckenstein $(2003,2005)$ considered specific ion effects via the change in the ion hydration between the bulk and the vicinity of the surface. Their approach can account for both the 
depletion of structure-making ions as well as for the accumulation of structure breaking ions near the air/water surface. According to the models mentioned above, electrostatic forces are of key importance for explaining the distribution of ionic species at the interface and hence the resulting surface tension. For example, at high salinity $(>0.2 \mathrm{M})$, differences in the hydration free energies of the ions lead to asymmetric ion depletions (Manciu and Ruckenstein, 2003) and therefore generate a macroscopic electrical potential. This electrical potential modifies the ionic distribution, and, consequently, the surface tension.

In some contexts, such as the geological sequestration of $\mathrm{CO}_{2}$ in deep saline aquifers, massive evaporation of native water may occur, generating residual brines having very high ionic strengths (Azaroual et al., 2004; see Andre et al., 2007 for further details). Furthermore, many systems encountered in industrial processes contain aqueous solutions of highly concentrated electrolytes (Azaroual et al., 1997; Azaroual et al., 2004). According to the Gibbs adsorption equation, the activity coefficient of the ionic species in the bulk water also influences the surface tension. Consequently, there is a need, especially at high ionic strength (>0.2 M), to take non-ideality into account. The Pitzer theory (Pitzer, 1973, 1995) and the resulting chemical equilibrium models of solution behaviour and solubility (Harvie and Weare, 1980; Harvie et al., 1984; Plummer et al., 1988; Felmy et al., 1994; Christov and Moller, 2004; Carroll et al., 2005) are particularly well-adapted to taking into account shortrange interactions between ions like, for example, the interaction of pairs of oppositely charged ions in the calculation of activity coefficients.

To our knowledge there has been no attempt, to date, to predict the surface tension of 1:1 electrolytes at high salinity using a mechanistic approach based on both the modified Poisson-Boltzmann and Pitzer theories. We propose here a unified and consistent model of the electrochemical properties of the air/water interface at high electrolyte concentrations. We take into account the specific influence of anions and cations close to the water's surface 
(structure-breaking and structure-making ions) on the calculation of the surface tension. After a brief description of the theoretical background, the model is validated by comparison with experimental surface tension data of $\mathrm{NaCl}, \mathrm{KCl}, \mathrm{HCl}, \mathrm{NaNO}_{3}, \mathrm{KNO}_{3}, \mathrm{HNO}_{3}$ aqueous electrolytic solutions. The specific physico-chemical properties of the ions constituting the different electrolytes at the interface and in the bulk are investigated.

\section{THEORETICAL BACKGROUND}

\subsection{Gibbs adsorption equation}

Under isobaric and isothermal conditions, the dependence of the surface (or interfacial) tension $\sigma$ (in $\mathrm{N} \mathrm{m}^{-1}$ ) on the electrolyte concentration can be calculated using the Gibbs adsorption equation (Weissenborn and Pugh, 1996; Li and Lu, 2001; Manciu and Ruckenstein, 2003)

$d \sigma=-\sum_{i} \Gamma_{i} d \mu_{i}=-\sum_{j \neq w} \Gamma_{j} d \mu_{j}-\Gamma_{w} d \mu_{w}$

where $\Gamma_{i}$ is the surface excess/deficiency of the species $i$, i.e. of ion (" $\left.j "\right)$ and water (" $w$ ") (in

sites $\mathrm{m}^{-2}$ ), and $\mu_{i}$ is the chemical potential of the species at the interface (in $\mathrm{J} \mathrm{mol}^{-1}$ ). The surface excess/deficiency of the species is expressed by (Manciu and Ruckenstein, 2005)

$\Gamma_{i}=\int_{0}^{5 x_{d}}\left[c_{i}(x)-c_{i}^{b}\right] d x$ 
where $c$ is the concentration (molarity in $\mathrm{mol} \mathrm{m}^{-3}$ ) and $x$ the distance of the species from the air/water surface corresponding to the Gibbs dividing surface (in $\mathrm{m}$ ). The superscript " $b$ " refers to concentration in the bulk water where electroneutrality occurs (not influenced by the air/water interface). The parameter $\chi_{d}$ represents the Debye length associated with the thickness of the diffuse layer (in $\mathrm{m}^{-1}$, see Hunter, 1981 for further details). We assume here a sharp air/water surface and step distributions for the ions at the interface.

A cross-sectional area of the Gibbs dividing surface contains the same number of moles of water between the air and water phases. Therefore, the Gibbs dividing surface is chosen so that $\Gamma_{w}=0$ sites $\mathrm{m}^{-2}$. This implies, according to equation (1):

$d \sigma=-\sum_{j \neq w} \Gamma_{j} d \mu_{j}$

The chemical potential of the ionic species at the air/water interface is considered equal to their chemical potential in the bulk electrolyte (Lyklema, 1991). This implies

$\mu_{j}=\mu_{j}^{b}$

$\mu_{j}=\mu_{0 j}^{b}+k_{b} T \ln \left(a_{j}^{b}\right)$,

where $k_{b}$ is the Boltzmann constant $\left(1.381 \times 10^{-23} \mathrm{~J} \mathrm{~K}^{-1}\right), T$ the temperature in $\mathrm{K}$, and $a$ the activity $\left(a_{j}^{b}=\gamma_{j}^{b} m_{j}^{b}\right.$ where $\gamma_{j}$ is the activity coefficient and $m$ the molality in mol $\mathrm{kg}_{\text {water }}{ }^{-1}$ of species $j$ ). The subscript " 0 " refers to the chemical potential in the standard state, i.e. the unit molar concentration of the ionic species at hypothetical infinite dilution (Helgeson et al., 1981). By combining equations (3) and (5), we obtain, at constant temperature and pressure, 


$$
d \sigma=-k_{b} T \sum_{j} \Gamma_{j} d a_{j}{ }^{b} / a_{j}{ }^{b}
$$

According to equation (6), the surface excess/deficiency of the ionic species and their activity in the bulk are key parameters to predict the surface tension of the solution at a given salinity. In the next chapters, we will explain how to calculate these parameters using the relevant theories.

\subsection{Ionic distributions at the air/water interface}

The modified Poisson-Boltzmann (MPB) equation enables the calculation of the ionic concentrations at the air/water interface (in $\mathrm{mol} \mathrm{m}^{-3}$ ). At thermodynamic equilibrium, they are described using a modified Boltzmann distribution (Manciu and Ruckenstein, 2003, 2005):

$c_{j}(x)=c_{j}^{b} \exp \left\{\frac{-\left[q_{j} \psi(x)+W_{j}(x)\right]}{k_{b} T}\right\}$,

where $q_{j}= \pm e z_{j}$ is the charge of species $j$ with $e$ the electronic charge $\left(1.602 \times 10^{-19} \mathrm{C}\right)$ and $z_{j}$ the valency, $\psi(x)$ the "mean electrical potential" (in V), and $W_{j}(x)$ an interaction free energy term (in $\mathrm{J}$ ) that includes all the other interactions of the ion with the surrounding medium. Hereafter, we consider only the effect of the electrical potential and the ionic hydration free energies on interfacial tension because our study is focused on highly saline solutions (ionic strengths $>1 \mathrm{M}$ ). Image charge interaction free energy (Onsager and Samaras, 1934) is not taken into account in our approach. Indeed, because of its dependence on the Debye length, the image force depends on the ionic strength of the solution and its amplitude decreases as the ionic strength increases. We also believe, using the approach of Manciu and Ruckenstein 
(2003), that specific ion effects on water structure can be explained by ionic hydration free energies. Other authors, such as Ninham and Yaminsky (1997) and Karraker and Radke (2002) consider that the Van der Waals interactions between an ion and the interface between two dielectric media (air and water) are not screened by the electrolyte and therefore might become greater than the image force at high salinity. However, as stated by Manciu and Ruckenstein (2003), this hypothesis leads to the debatable prediction that the cations would draw nearer to the interface than the anions. Also, in our modeling approach, the ion correlation effects associated with the exclusion volume of the ions, which could be very important at high electrolyte concentration, is neglected. To include the ion correlation effects, both the modified Poisson-Boltzmann (Bhuiyan et al., 1991; Kralchevsky and Paunov, 1992) and density functional theories (Forsman, 2009; Peng and $\mathrm{Yu}, 2009$ ) can be used.

According to Poisson's equation, which considers the electrostatic interactions associated with the volume charge density $\rho$ (in $\mathrm{C} \mathrm{m}^{-3}$ ) (Hunter, 1981), the Laplacian of the electrical potential can be described by

$\nabla^{2} \psi=-\frac{\rho}{\varepsilon_{w}}=-\frac{\sum_{j} q_{j} c_{j}}{\varepsilon_{w}}$,

where $\varepsilon_{w}$ is the dielectric permittivity of water $\left(\varepsilon_{w}=\sim 78.3 \times 8.85 \times 10^{-12} \mathrm{~F} \mathrm{~m}^{-1}\right.$ at $298 \mathrm{~K}$ and at a pressure of 1 bar). For simplicity, like Manciu and Ruckenstein (2003, 2005), we consider a uniform dielectric constant of value $\varepsilon_{w}$ at the air/water interface. Large electrical fields and concentrations of counterions near the surface actually induce a decrease of the dielectric constant. Indeed, the presence of an electrolyte hinders the polarizability of the water molecules, thus decreasing the dielectric constant. In our model, the influence of the dielectric constant of water at the interface on the ionic distribution is taken into account by the 
interaction free energy term in equation (7). Note that the substantial reorientation and restructuring of surface water molecules significantly diminishes the dielectric constant (Jungwirth and Tobias, 2006). Combining equations (7) and (8) leads to the non-linear modified Poisson-Boltzmann equation:

$\nabla^{2} \psi(x)=-\frac{1}{\varepsilon_{w}} \sum_{j} q_{j} c_{j}^{b} \exp \left\{\frac{-\left[q_{j} \psi(x)+W_{j}(x)\right]}{k_{b} T}\right\}$.

The electrical potential near the surface is solved numerically using equation (9) and the following boundary conditions

$\left.\nabla \psi\right|_{x=0}=0$,

$\psi(x)=0$ at $x=x_{\max }$,

where $x_{\max }$ is about 5 Debye-Hückel lengths from the air/water surface (Manciu and Ruckenstein, 2005). The previous system of equations (equations (9) to (11)) is solved in our study using a Partial Differential Equations (PDE) solver based on the finite-element method (the Electrostatic module of COMSOL Multiphysics ${ }^{\mathrm{TM}}$ 3.4).

Equation (9) assumes that there is no surface charge density at the air/water surface. However, at low salinity $\left(<10^{-2} \mathrm{M}\right)$, the surface adsorption of $\mathrm{OH}^{-}$ions may not be neglected (Karraker and Radke, 2002; these authors specifically consider adsorbed hydroxide ions, which lose part of their hydration shells). This generates a surface charge. According to Jungwirth and Tobias (2006), on average, surface water molecules have a net orientation of their dipoles and contribute, therefore, to a macroscopic electrical potential at the air/water interface. Indeed, surface water molecules are reoriented and restructured to maximize their 
hydrogen bonding in the under-coordinated environment, as opposed to their isotropic orientation in the bulk. A positive value of the electrical potential of pure water indicates that the liquid is positive relative to vapour and that surface water molecules are oriented with their hydrogen atoms pointing towards the water phase. Consequently, adsorption sites for hydroxide ions may be sparsely spaced groups of surface water molecules available for hydrogen bonding with the hydroxide oxygen. On the other hand, Jungwirth and Tobias (2006) stated that a significant percentage of surface water molecules $(\sim 19 \%)$ might possess free $\mathrm{OH}$ bonds. Nevertheless, by adding an electrolyte, other interactions may dominate the surface charge generated by adsorption of hydroxide ions or by free $\mathrm{OH}$ bonds. According to Karraker and Radke (2002), the presence of $\mathrm{OH}^{-}$ions at the interface generates a surface charge of extremely low amplitude. Therefore, at high salinity, following the approach of Manciu and Ruckenstein (2003), the surface charge density can be neglected.

After determining the electrical potential $\psi(x)$, we can calculate the ionic concentrations $c_{j}(x)$ at the interface (equation (7)) using a given value for $W_{j}(x)$. By integrating the difference between the ionic concentrations at a distance $x$ from the surface and the ionic concentrations in the bulk electrolyte, we can predict the excess/deficiency of the ionic species near the surface (equation (2)).

\subsection{Surface tension of $1: 1$ electrolytes}

For binary electrolytes, the surface tension variation with the electrolyte concentration can be obtained using equation (3):

$$
d \sigma=-\Gamma_{\mathrm{M}} d \mu_{\mathrm{M}}^{b}-\Gamma_{\mathrm{X}} d \mu_{\mathrm{X}}^{b}
$$


By incorporating equation (5) and the equation $a_{j}^{b}=\gamma_{j}^{b} m_{j}^{b}$ in equation (12), where $\gamma_{j}$ is the activity coefficient of species $j$, we find:

$d \sigma=-k_{b} T\left[\Gamma_{\mathrm{M}}\left(d \ln \gamma_{\mathrm{M}}^{b}+d \ln m_{\mathrm{M}}^{b}\right)+\Gamma_{\mathrm{X}}\left(d \ln \gamma_{\mathrm{X}}^{b}+d \ln m_{\mathrm{X}}^{b}\right)\right]$.

For $1: 1$ electrolytes like $\mathrm{NaCl}$ or $\mathrm{KCl}$, the molalities of the cations and anions are equal in the bulk water, i.e. $m_{\mathrm{M}}^{b}=m_{\mathrm{X}}^{b}=m_{\mathrm{MX}}^{b}$. This implies, according to equation (13):

$d \sigma=-k_{b} T\left[\Gamma_{\mathrm{M}} d \ln \gamma_{\mathrm{M}}^{b}+\Gamma_{\mathrm{X}} d \ln \gamma_{\mathrm{X}}^{b}+\left(\Gamma_{\mathrm{M}}+\Gamma_{\mathrm{X}}\right) d \ln m_{\mathrm{MX}}^{b}\right]$

We also assume that the activity coefficients of cations and anions are equal (see Appendix A). This gives:

$d \sigma=-k_{b} T\left(\Gamma_{\mathrm{M}}+\Gamma_{\mathrm{X}}\right)\left(d \ln \gamma_{\mathrm{MX}}^{b}+d \ln m_{\mathrm{MX}}^{b}\right)$.

The equation for the estimation of the surface tension as a function of the electrolyte concentration can be obtained by integrating equation (15):

$$
\begin{aligned}
& \Delta \sigma=\sigma-\sigma_{w}=\int_{\sigma_{w}}^{\sigma} d \sigma=-k_{b} T\left[\int_{1}^{\gamma_{\mathrm{Mx}}}\left(\Gamma_{\mathrm{M}}+\Gamma_{\mathrm{X}}\right) d \ln \gamma_{\mathrm{MX}}^{b}+\int_{0}^{m_{\mathrm{MX}}}\left(\Gamma_{\mathrm{M}}+\Gamma_{\mathrm{X}}\right) d \ln m_{\mathrm{MX}}^{b}\right], \\
& \Delta \sigma=-k_{b} T \int_{0}^{m_{\mathrm{MX}}}\left(\Gamma_{\mathrm{M}}+\Gamma_{\mathrm{X}}\right)\left(\frac{d \ln \gamma_{\mathrm{MX}}^{b}}{d m_{\mathrm{MX}}^{b}}+\frac{1}{m_{\mathrm{MX}}^{b}}\right) d m_{\mathrm{MX}}^{b},
\end{aligned}
$$


where $\sigma$ is the surface tension at a given electrolyte concentration and $\sigma_{w}$ the surface tension of pure water. According to equation (17), the excess/deficiency of the ionic species at the interface and the variation of the natural logarithm of their activity coefficient with their molality are key parameters for predicting surface tension variation. The molarities of cations and anions (in $\mathrm{mol} \mathrm{m} \mathrm{m}^{-3}$ ) are also equal in the bulk electrolyte and this gives, using equation (2):

$\Gamma_{\mathrm{M}}+\Gamma_{\mathrm{X}}=\int_{0}^{5 x_{d}}\left[c_{\mathrm{M}}(x)+c_{\mathrm{X}}(x)-2 c_{\mathrm{MX}}^{b}\right] d x$

By combining equations (17) and (18), we have:

$\Delta \sigma=-k_{b} T \int_{0}^{m_{\mathrm{MX}}}\left\{\int_{0}^{5 \chi_{d}}\left[c_{\mathrm{M}}(x)+c_{\mathrm{X}}(x)-2 c_{\mathrm{MX}}^{b}\right] d x\left(\frac{d \ln \gamma_{\mathrm{MX}}^{b}}{d m_{\mathrm{MX}}^{b}}+\frac{1}{m_{\mathrm{MX}}^{b}}\right)\right\} d m_{\mathrm{MX}}^{b}$.

To summarize, in order to predict the surface tension variation with the salinity in the case of 1:1 electrolytes, we must (i) determine the surface excess/deficiency of the ionic species (molarity, in mol $\mathrm{m}^{-3}$ ), (ii) calculate the activity coefficients in the bulk water (see equations (A1) to (A11), (B1) to (B5), and Table 1 for further details), and (iii) integrate equation (15) from the molality of pure water to the molality of the bulk electrolyte (equation (19)). We also need to convert molarities $\left(\mathrm{mol} \mathrm{m}^{-3}\right)$ into molalities (mol $\left.\mathrm{kg}_{\text {water }}{ }^{-1}\right)$ (equations (C1) and (C2)). Standard partial molal volumes of water and ionic species at a given temperature and pressure ( 1 bar) were calculated using the "Thermo-ZNS" computer code (Lassin et al., 2005) (Table 2). This code was developed to determine the relevant thermodynamic properties of water, aqueous species, minerals and gases in capillary systems where interfacial phenomena are of primary importance. Standard partial molal volumes of 
water and ionic species as a function of temperature and pressure are determined using the revised Helgeson-Kirkham-Flowers (HKF) model (Helgeson et al., 1981) for predicting the standard partial molal properties of the species (Tanger and Helgeson, 1988). This thermodynamic model takes into account the temperature and pressure dependence of the solvent structure (up to $1000{ }^{\circ} \mathrm{C}$ and a pressure of $5 \mathrm{kbar}$ ). According to Tanger and Helgeson (1988), the standard partial molal volume of an aqueous ion or electrolyte can be expressed by its nonsolvation and solvation contribution. The electrostatic solvation properties of an ion can be discussed by considering the sign of the solvation contribution to the standard partial molal volume. For example, as seen in Table 2, sodium has a negative standard partial molal volume and is considered to be an electrostatic "negative solvating ion".

\subsection{Structure-making and structure-breaking ions}

The surface tension of an inorganic aqueous electrolyte can increase or decrease with the electrolyte concentration. According to the Gibbs adsorption equation, these variations depend on the ionic distribution at the air/water interface, i.e. the possible depletion of the structure-making ions and the positive adsorption of the structure-breaking ions. Are the cations and/or the anions negatively or positively adsorbed near the surface? Positive or negative $d \sigma / d m$ values do not necessarily mean that both cations and anions are negatively or positively adsorbed, but that one ion may be predominate in terms of overall adsorption and effect on surface tension. Recent molecular dynamics simulations have shown that the common belief that the interfacial region is depleted of ions might not be true (Jungwirth and Tobias, 2001).

The close correlation between the magnitude of $d \sigma / d m$ and hydration entropy and enthalpy of the salts in the bulk water has been observed (Hey et al., 1981; Weissenborn and 
Pugh, 1996). The most important property of liquid water is its unique ability to form a network of self-associated molecules through hydrogen bonding. Small ions of high valency are highly hydrated and increase the organization of water molecules by compacting water molecules around themselves. They are commonly called structure-making ions. Large ions of low valency are weakly hydrated, have the opposite effect on water's structure and are commonly called structure-breaking ions. It is generally accepted that the oxygen atoms of water molecules surrounding the solvated ion are oriented toward the cations or the hydrogen atoms toward the anions. In this case, the water molecules in the first hydration shell are oriented in the strong electric field of the ion (see Fig. 1), and the 3D network of water molecules is interrupted. Structure-making ions impose more local ordering in surrounding water, i.e. they strengthen the hydrogen bonds between them, while structure breaking ions disorder them. In fact, the surface properties of anions and cations are due to several factors, of which ion size and ion and water polarizability dominate (Boström et al., 2001; Hribar et al., 2002; Karraker and Radke, 2002; Boström et al., 2005; Jungwirth and Tobias, 2006). According to Collins (1985) and Hribar et al. (2002) charge densities and a balance of electrostatic and hydrogen bonding forces control the effects of ions on water structure. These forces are due to water's dipole interacting with ions and neighbouring water molecules, respectively. Ion-water interactions are dominated by charge density effects, and water-water interactions are dominated by hydrogen bonding. Structure-making ions are expected to stay in the bulk water because they can better organize the water dipoles in the bulk water than at the interface, and structure-breaking ions are expected to be pushed to the surface by the bulk water.

Two of the model's parameters are of primary importance if we wish to describe the effect of ion hydration on interfacial tension: a length that corresponds either to the distance of closest approach of a structure-making ion or to the thickness of a layer of positive 
adsorption of structure-breaking ions, $d_{j}$ (in $\AA$ ), and an interaction free energy term, $W_{j}$, of the ion $j$ (in J; see Fig. 2). We use the approach of Manciu and Ruckenstein (2003). These authors explain the physico-chemical meaning of these parameters. The distribution of ions in the vicinity of the surface can be calculated if reasonable estimations of $d_{j}$ and $W_{j}$ are available. The hydration free energy per ion, in bulk water, is of the order of $\sim 100-200 k_{b} T$ (Markin and Volkov, 2002; Manciu and Ruckenstein, 2003). The hydration free energy of a structuremaking ion increases by a few $k_{b} T$ from its bulk hydration free energy at a distance $d_{j}$ from the air/water surface (Manciu and Ruckenstein, 2003). This variation of the hydration free energy corresponds to only a fraction of the total ion hydration free energy, but can still be sufficient to cause a significant depletion of ions in the aqueous interface (Markin and Volkov, 2002; Jungwirth and Tobias, 2006). Conversely, the hydration free energy of a structure-breaking ion decreases by a few $k_{b} T$ from its bulk hydration free energy at a distance $d_{j}$ from the air/water surface (Manciu and Ruckenstein, 2003, 2005).

\section{COMPARISON WITH EXPERIMENTAL DATA}

Surface tension data for aqueous electrolyte solutions available in the literature are used to validate the model. Abramzon and Gaukhberg (1993) reported surface tension data for 179 simple inorganic electrolytes (at various temperatures between 0 and $100{ }^{\circ} \mathrm{C}$ and at a pressure of 1 bar) over a wide concentration range (from 0 to $36 \mathrm{M}$ ).

\section{1. $\mathrm{NaCl}$ electrolyte}

The NaCl-electrolyte surface tension data from Abramzon and Gaukhberg (1993) show a near-linear tendency of the surface tension to increase with the electrolyte 
concentration up to a salinity of $3 \mathrm{~mol} \mathrm{~kg}_{\mathrm{water}}{ }^{-1}$. There may, therefore, be a zone depleted of ions at the air/water interface.

Recent molecular dynamics simulations (Jungwirth and Tobias, 2001, 2006) have shown the accumulation of large negative anions (e.g. $\mathrm{Br}^{-}$or $\left.\mathrm{I}^{-}\right)$near the air/water surface and the depletion in this area of some cations (e.g. $\mathrm{Na}^{+}$). According to these simulations, chloride ions penetrate the interface but are slightly repelled from the surface. Anions near the surface are still solvated, maintaining a substantial solvation shell. Chlorides do not, however, exhibit a significant concentration peak at the air/water interface. On the other hand, sodium is strongly repelled from the surface. Consequently, a resulting electrical double layer exists at the interface. We, therefore, consider that the cations are negatively adsorbed at the interface (structure-making) and that the anions can penetrate it, i.e. $d_{\mathrm{M}}>d_{\mathrm{X}}, W_{\mathrm{X}}=\infty k_{b} T$ for $0<x<d_{\mathrm{X}}$ and $W_{\mathrm{M}}=\infty k_{b} T$ for $0<x<d_{\mathrm{M}}$. There are three layers at the air/water interface: the uppermost layer having a thickness $d_{\mathrm{X}}$ (I) depleted of ions, a layer having a thickness $d_{\mathrm{M}}-d_{\mathrm{X}}$ (II) made up solely of chlorides, and a layer having a thickness $5 \chi_{d}$ (III) where ionic concentrations are described according to the classical Gouy-Chapman theory (Gouy, 1910; Chapman, 1913).

In order to determine the electrical potential at the air/water interface, we solve the modified Poisson-Boltzmann equation (equation (9)) and the classical Poisson-Boltzmann equation numerically using the boundary conditions (equations (10), (11), and continuity of the electrical potential between the layers I, II, and III). The electrical potential is calculated using the following equations:

$$
\frac{d^{2} \psi_{\mathrm{I}}}{d x^{2}}=0,0<x<d_{\mathrm{X}}
$$




$$
\frac{d^{2} \psi_{\mathrm{II}}}{d x^{2}}=\frac{e c_{\mathrm{MX}}^{b} N_{a}}{\varepsilon_{w}} \exp \left(e \psi_{\mathrm{II}} / k_{b} T\right), d_{\mathrm{X}}<x<d_{\mathrm{M}},
$$

$$
\frac{d^{2} \psi_{\mathrm{III}}}{d x^{2}}=\frac{2 e c_{\mathrm{MX}}^{b} N_{a}}{\varepsilon_{w}} \sinh \left(e \psi_{\mathrm{III}} / k_{b} T\right), d_{\mathrm{M}}<x<x_{\max }=5 \chi_{d},
$$

$$
\left.\frac{d \psi_{\mathrm{I}}}{d x}\right|_{x=0}=0
$$

$\psi_{\mathrm{I}}=\psi_{\mathrm{II}}$ and $\psi_{\mathrm{II}}=\psi_{\mathrm{III}}$ for $x=d_{\mathrm{X}}$ and $x=d_{\mathrm{M}}$, respectively, and

$$
\psi_{\text {III }}=0 \text { at } x=x_{\max } .
$$

The surface excess/deficiency of anions and cations are calculated using the electrical potential and equations (7), (18) thus determined. Using the Pitzer parameters (Table 1), we estimate the variation of the activity coefficients with the molality in the bulk water (see equations (A1) to (A11) and equations (B1) to (B5)). Molarities ( $\mathrm{mol} \mathrm{m}{ }^{-3}$ ) must also be converted into molalities ( $\mathrm{mol} \mathrm{kg}_{\mathrm{water}}{ }^{-1}$ ) (equations $(\mathrm{C} 1)$ and $(\mathrm{C} 2)$ ). Partial molal volumes of water and ionic species at a given temperature and pressure ( 1 bar here) were calculated using the "Thermo-ZNS" computer code (Lassin et al., 2005) (Table 2). The surface tension variation with the salinity was determined using equation (19).

A sensitivity analysis is done by varying the value of $d_{\mathrm{M}}$ and keeping $d_{\mathrm{X}}$ constant (Fig. 3a). As expected, the surface tension increases significantly with the distance of closest approach $d_{\mathrm{M}}$. We observe the same trend by varying the value of $d_{\mathrm{X}}$ and keeping $d_{\mathrm{M}}$ constant (Fig. 3b). However, in this case, the predictions are more sensitive to the distance of closest approach of cations than that of anions, particularly at high salinity. 
Only the values of $d_{\mathrm{X}}$ and $d_{\mathrm{M}}$ are optimized in the case of the $\mathrm{NaCl}$ electrolyte. We fit the surface tension data with the Simplex algorithm (Caceci and Cacheris, 1984) to obtain the posterior values of the parameters. The algorithm minimizes a cost function $R$ defined in a least square sense. The forward problem, solved by COMSOL Multiphysics ${ }^{\mathrm{TM}} 3.4$, is coupled with an optimization routine written in a MatLab routine (Fig. 4). We use the a-priori values of Manciu and Ruckenstein (2003) for $d_{\mathrm{X}}$ and $d_{\mathrm{M}}$, i.e. $d_{\mathrm{X}}=2 \AA$ and $d_{\mathrm{M}}=5 \AA$.

The model predictions of the surface tension variations and the experimental data are in very good agreement for the entire salinity range, especially if the increasing value of the activity coefficient at high salinity is taken into account (Fig. 5). Indeed, using the Pitzer theory (Pitzer and Mayorga, 1973) enables us to predict the experimental data at high salinity ( $>3 \mathrm{~mol} \mathrm{~kg}_{\text {water }}{ }^{-1}$ ) rather well. Fig.6 presents also the cost function $R$ for different values of $d_{\mathrm{Cl}}$ and $d_{\mathrm{Na}}$.

We use a distance of minimum approach for the cations $\left(d_{\mathrm{M}}\right)$ of $4.25 \pm 0.5 \AA$. This value is similar to the value obtained by Manciu and Ruckenstein (2003) (5 $\AA$ ), and corresponds approximately to the effective diameter of sodium ( $4.09 \AA$ according to Marcus, 1987, and Shock and Helgeson, 1988) (Table 3). This distance of closest approach corresponds also to the thickness of the "layer" where the water density profile changes (thickness of two water molecules, roughly between $4 \AA$ and $6 \AA$, Jungwirth and Tobias, 2001; Boström et al., 2005). The ion hydration free energy increases when the ion moves into this region (with a lower water density than in the bulk) and structure-making ions, therefore, prefer to stay in the bulk. We use $d_{\mathrm{X}}=1 \pm 0.25 \AA$ for the distance of closest approach of anions. Note that, by using $d_{\mathrm{M}}=4.1 \AA$ and $d_{\mathrm{X}}=1.5 \AA$, we obtain also a very good agreement between the model predictions and the experimental data (see Fig. 6).

Fig. $7 \mathrm{a}$ and $7 \mathrm{~b}$ show the corresponding electrical potential and ionic concentration profiles. The asymmetric ion depletions create a surface electrical potential, even in the 
absence of any "initial surface charge" (by comparison with ion complexation processes on solid surfaces, Sverjensky, 2006). The charge generating the diffuse double layer is located a few Angströms from the surface and is due to the presence of the anions. The resulting electrical potential is negative, and its amplitude at interface increases with the salinity.

In order to check the validity of the previously optimized parameters, we use the same value of $d$ and $W$ for chlorides to predict the surface tension variation of $\mathrm{KCl}$ and $\mathrm{HCl}$ aqueous solutions (Fig. 8).

\section{2. $\mathrm{KCl}$ and $\mathrm{HCl}$ electrolytes}

The model predictions were compared to the surface tension data for $\mathrm{KCl}$ and $\mathrm{HCl}$ aqueous electrolyte solutions. In our model, chlorides are absent in a layer $1 \AA$ thick and we also assume that the effect of the potassium cation on the structure of water is similar to that of sodium (structure-making ions). Indeed, sodium and potassium have the same electrical charge and their effective electrostatic radii are relatively similar (Table 3). Furthermore, recent molecular dynamics simulations for $\mathrm{KNO}_{3}$ electrolytes have predicted a thick layer ( $5 \AA$ ) depleted of potassium (Dang et al., 2006).

The calculation of the surface distribution of hydrogen is a particular case because $\mathrm{H}^{+}$ cannot exist alone, except in isolation inside a high vacuum. The ionic radius of $\mathrm{H}^{+}$is several orders of magnitude smaller than that of other ions ( $\mathrm{Li}$ et al., 2008). When hydrogen approaches another atom or molecule, it can distort the other's electron cloud. $\mathrm{H}^{+}$must be attached to another atom or molecule that possesses a lone pair of electrons. The proton, as an electron acceptor, can be stabilized as in pyramidal hydronium ions (or hydroxonium) $\mathrm{H}_{3} \mathrm{O}^{+}$. According to some authors (e.g. Weissenborn and Pugh, 1996; Manciu and Ruckenstein, 
2005; Jungwirth and Tobias, 2006), $\mathrm{H}_{3} \mathrm{O}^{+}$ions can be positively adsorbed at the air/water interface. Consequently, we consider that these ions are structure-breaking ions.

For the $\mathrm{KCl}$ electrolyte, we use equations (20) to (25) to determine the electrical potential at a given salinity, and equations (7), (B1) to (B5), (C1), (C2) and (19) to calculate the surface tension variations with the salinity. For the $\mathrm{HCl}$ electrolyte, the electrical potential in the three surface layers is calculated using equation (9) with, respectively, $W_{\mathrm{M}}=-1 k_{b} T$ (apriori value from Manciu and Ruckenstein, 2005), $W_{\mathrm{X}}=\infty k_{b} T$ for $0<x<d_{\mathrm{X}}, W_{\mathrm{M}}=-1 k_{b} T$ and $W_{\mathrm{X}}=0 k_{b} T$ for $d_{\mathrm{X}}<x<d_{\mathrm{M}}, W_{\mathrm{M}}=W_{\mathrm{X}}=0 k_{b} T$ for $x>d_{\mathrm{M}}$ and the boundary conditions (equations (10) and (11)).

There is a good agreement between the model calculations and the data for the entire salinity range (Figs. 9 and 10). In the case of the $\mathrm{KCl}$ electrolyte, we use a distance of closest approach for the cations of $4.5 \pm 0.5 \AA$. This corresponds approximately to the effective electrostatic diameter of potassium $(\sim 4.4 \AA$ according to Marcus, 1987 and Shock and Helgeson, 1988, Table 3). We also compare the effect of the activity coefficient $\gamma$ on the surface tension predictions using the Pitzer model (Pitzer and Mayorga, 1973 and Christov and Moller, 2004, for $\mathrm{KCl}$ and $\mathrm{HCl}$ electrolytes, respectively). For a $\mathrm{KCl}$ aqueous solution, the effect of the activity coefficient on the surface tension variations is negligible. This is not the case for the $\mathrm{HCl}$ electrolyte whose activity coefficient significantly decreases the predicted surface tension values at high ionic strength $\left(>1 \mathrm{~mol} \mathrm{~kg}_{\text {water }}{ }^{-1}\right)$, and taking into account this correction strongly improves the predictions. For the $\mathrm{HCl}$ electrolyte, the Pitzer coefficients are adjusted using an iterative procedure (see Appendix A for more details). Note that we obtain also a good agreement between the model predictions and the data using $d_{\mathrm{K}}=$ $4.4 \AA$ and $d_{\mathrm{Cl}}=1.5 \AA$. In the case of the $\mathrm{HCl}$ electrolyte, an increasing value of the distance of closest approach leads to a diminution of the amplitude of the interaction free energy term. For example, the model predictions are in good agreement with the experimental data using 
$d_{\mathrm{H}}=2 \AA$ and $W_{\mathrm{H}}=-1 k_{b} T$ or $d_{\mathrm{H}}=8 \AA$ and $W_{\mathrm{H}}=-0.2 k_{b} T$. Consequently, we decide to take the value of the effective electrostatic diameter of hydronium for $d_{\mathrm{H}}$ (see Table 3 ) and we optimize the value of $W_{\mathrm{H}}$. Finally, we obtain $d_{\mathrm{H}}=6.2 \AA$ and $W_{\mathrm{H}}=-0.3 k_{b} T$. For $\mathrm{HCl}$, the distances of minimum approach of cations and anions are very close each other and the amplitude of the depth of the potential well is low. Therefore, the "double layer effect" associated with the asymmetric distribution of charges at interface is weak comparing to the $\mathrm{NaCl}$ electrolyte. This hypothesis is in agreement with recent molecular dynamics simulations (Mucha et al., 2005): the singlet density profiles of hydronium and chlorides are very close each other and the resulting surface electrostatic potential is weak (Marcelja, 2006). In our approach, we have also neglected ion correlation effects which can be very important at high ionic strength. This assumption may lead to some uncertainties concerning the optimized parameter values.

\section{3. $\mathrm{NaNO}_{3}, \mathrm{KNO}_{3}$, and $\mathrm{HNO}_{3}$ electrolytes}

Chloride anions were then replaced by nitrates. The study of the behaviour of nitrates at the air/water interface for sea salt aerosols is a topic of great interest to atmospheric scientists (Thomas et al., 2007; Brown et al., 2009). Pegram and Record (2006), in their analysis of surface tension data, have suggested that the concentration of nitrate ions at the interface is the same as in the bulk. Computational studies of $\mathrm{NO}_{3}{ }^{-}$at the aqueous interface have produced conflicting results concerning its distribution. In 2003, molecular dynamics (MD) simulations (polarizable force field) predicted that nitrate anions prefer interfacial to bulk solvation in aqueous solutions (Salvador et al., 2003). Recent MD simulations at high electrolyte concentration (up to $6.8 \mathrm{M}$ of $\mathrm{NaNO}_{3}$, Thomas et al., 2007), however, predict a decreased interfacial nitrate concentration (Dang et al., 2006; Thomas et al., 2007). Is $\mathrm{NO}_{3}{ }^{-}$ 
present at the surface of aqueous $\mathrm{NaNO}_{3}$ solutions? As opposed to chloride, which is a monoatomic ion, nitrate is a polyatomic ion composed of one nitrogen and three oxygen atoms. Thus, nitrate presents an anisotropic molecular polarizability with a large difference between the in-plane and out-of-plane components. The factors stabilizing the bulk versus interfacial solvation of $\mathrm{NO}_{3}{ }^{-}$are more complex than those in the case of spherical ions due to multiple hydrogen-bonding sites and also differences in size and shape. The back-and-forth nature of the simulations leaves the debate over the surface propensity of nitrate anions unresolved, and quantitative experimental results have been slow to follow. Brown et al. (2009) used depth resolved X-ray photoemission spectroscopy (XPS) of deliquesced singlecrystal samples to provide the most quantitative determination of ion concentration profiles at the liquid-vapor interface of sodium nitrate solutions. They found that the top surface layers

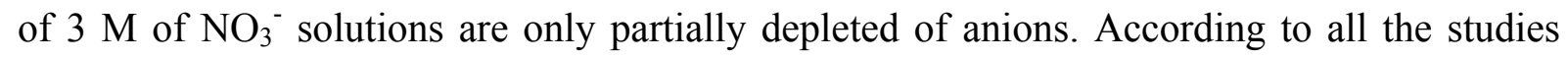
previously cited, the question regarding the surface propensity of nitrate anions remains unresolved.

Consequently, nitrate is initially assumed to behave like chloride at the air/water interface (a-priori value of $d_{\mathrm{X}}=1 \AA$ and $W_{\mathrm{X}}=\infty k_{b} T$ in the uppermost layer). We use the same parameter values as previously for the cations, i.e. $d_{M}=4.25 \AA$ for $\mathrm{Na}^{+}$(structure-making), 4.5 $\AA$ for $\mathrm{K}^{+}$(structure-making), and $6.2 \AA$ for $\mathrm{H}^{+}$(structure-breaking with $W_{\mathrm{M}}=-0.3 k_{b} T$ ).

The model predictions for the surface tension, the activity coefficient, and the corresponding experimental data are shown in Fig. 11, 12 and 13. The model calculations are in good agreement with the experimental data. All the surface tension data for nitrates are lower than those for chlorides, especially at high salinity $\left(>2 \mathrm{~mol} \mathrm{~kg}_{\mathrm{water}}{ }^{-1}\right)$. The optimized value for the distance of closest approach of nitrate $\left(d_{\mathrm{X}}\right)$ is 0 . Table 4 summarizes the values of the optimized parameters for each ionic species. In the case of the $\mathrm{KNO}_{3}$ electrolyte, the effect of the activity coefficient on the surface tension is very strong and divides it 
approximately in two at high salinity $\left(>3 \mathrm{~mol} \mathrm{~kg}^{-1}\right.$ water). The activity coefficient significantly influences the surface tension predictions for $\mathrm{NaNO}_{3}, \mathrm{KNO}_{3}$, and $\mathrm{HNO}_{3}$ electrolytes. This is probably due to the polyatomic nature of nitrate. For $\mathrm{HNO}_{3}$ electrolyte, the model predictions correspond to the experimental data up to a salinity of $30 \mathrm{~mol} \mathrm{~kg}_{\text {water }}{ }^{-1}$.

\section{CONCLUSION}

We have developed a new model to predict the surface tension variation of $1: 1$ electrolytes at high salinity. According to the Gibbs adsorption equation, the excess/deficiency of the ionic species at the air/water interface and their activities in the bulk water are responsible for the variation of the surface tension with the salinity.

The modified Poisson-Boltzmann and Pitzer equations are used to determine the ionic distributions at interface and the activity coefficients, respectively. The resulting electrochemical model needs only two parameters (two parameters for each ion; four parameters for 1:1 electrolytes) which depend on the effect of ions on water's structure: a length corresponding to the distance of closest approach of structure-making ion or to the thickness of a layer of positive adsorption of structure-breaking ions, and an interaction free energy term (positive for structure-making and negative for structure-breaking ions).

The model predictions are in good agreement with the surface tension data for $\mathrm{NaCl}$, $\mathrm{KCl}, \mathrm{HCl}, \mathrm{NaNO}_{3}, \mathrm{KNO}_{3}$, and $\mathrm{HNO}_{3}$ electrolytes. We consider that sodium and potassium are absent in a layer corresponding to the size of their effective electrostatic diameter. The thickness of this layer also corresponds, according to molecular dynamics, to the size of a layer where the density and orientation of water molecules are different from that of the bulk water. Chlorides and nitrates, which have larger ionic radii than sodium and potassium, are assumed to be present at the air/water surface. On the other hand, protons, because of their 
very small ionic radii, are complexed with water molecules to form hydronium ions. These ions are considered to be structure-breaking ions and are consequently positively adsorbed at the interface.

The study of the influence of the activity coefficient on the surface tension behaviour is of particular importance in the salinity domain investigated here. Taking the activity coefficient into account leads to a substantial decrease in the surface tension (except for the $\mathrm{KCl}$ electrolyte and the case of the $\mathrm{NaCl}$ electrolyte where the activity coefficient significantly increases the surface tension at high salinity). This effect is very strong for electrolytes containing hydronium and nitrate. This might be related to the polyatomic nature of hydronium and nitrate.

In future work, we will develop our model to study the surface tension of mixed aqueous solutions, and multivalent ionic species. The model will also include ion correlation effects which can be very important at high ionic strength.

\section{Acknowledgments}

This study was done within the framework of the "Proche Puits" Project co-funded by the French National Research Agency (ANR). We thank very much C. Christov for fruitful discussions and for his useful comments. P. Leroy thanks A. Bolève, D. Jougnot, and N. Linde. We thank also the two anonymous referees and the associated editor for their very constructive reviews of this manuscript. 


\section{APPENDIX A}

The Pitzer theory (Pitzer, 1973, 1995) enables the determination of the activity coefficients $\gamma_{j}$ in the bulk electrolyte. In the case of completely dissociated 1:1 electrolytes and according to Harvie and Weare (1980) and Plummer et al. (1988):

$$
\begin{aligned}
& \ln \gamma_{\mathrm{X}}^{b}=\ln \gamma_{\mathrm{M}}^{b}=\ln \gamma_{\mathrm{MX}}^{b}=F+m_{\mathrm{X}}^{b}\left[2 B_{\mathrm{MX}}+\left(m_{\mathrm{M}}^{b}+m_{\mathrm{X}}^{b}\right) C_{\mathrm{MX}}\right]+m_{\mathrm{M}}^{b} m_{\mathrm{X}}^{b} C_{\mathrm{MX}}, \\
& F=-A^{\phi}\left[\frac{\sqrt{I}}{1+b \sqrt{I}}+\frac{2}{b} \ln (1+b \sqrt{I})\right]+m_{\mathrm{M}}^{b} m_{\mathrm{X}}^{b} B_{\mathrm{MX}}^{\prime},
\end{aligned}
$$

$A^{\phi}=\frac{1}{3}\left(\frac{2 \pi N_{a} d_{w}}{1000}\right)^{1 / 2}\left(\frac{e^{2}}{\varepsilon_{w} k_{b} T}\right)^{3 / 2}$,

$z_{\mathrm{M}} m_{\mathrm{M}}^{b}+m_{\mathrm{H}^{+}}^{b}=z_{\mathrm{X}} m_{\mathrm{X}}^{b}+m_{\mathrm{OH}^{-}}^{b}$,

$$
I=\frac{1}{2} \sum_{j} z_{j}{ }^{2} m_{j}^{b}=\frac{1}{2}\left(m_{\mathrm{M}}^{b}+m_{\mathrm{X}}^{b}+m_{\mathrm{H}^{+}}^{b}+m_{\mathrm{OH}}^{b}\right)
$$

where $I$ is the ionic strength (in mol $\mathrm{kg}_{\text {water }}{ }^{-1}$ ), $b$ an empirical parameter with a value of 1.2 and $A^{\phi}$ the Debye-Hückel coefficient $\left(0.388\right.$ and 0.391 for $T=20^{\circ} \mathrm{C}$ and $25^{\circ} \mathrm{C}$, respectively, and a pressure of 1 bar using the "Thermo-ZNS" computer code; Lassin et al., 2005). The DebyeHückel coefficient depends on the density $d_{w}\left(\right.$ in $\mathrm{kg} \mathrm{m}^{-3}$ ) and the dielectric constant $\varepsilon_{w}$ (in $\mathrm{F}$ $\mathrm{m}^{-1}$ ) of pure water. The subscript "M" denotes cations, " $\mathrm{X}$ " denotes anions, and $N_{a}$ is the Avogadro number $\left(\sim 6.02 \times 10^{23}\right.$ sites $\left.\mathrm{mol}^{-1}\right)$. According to equations (A4) and (A5), the ionic 
strength at high salinity can be written $I \cong 0.5\left(m_{\mathrm{M}}^{b}+m_{\mathrm{X}}^{b}\right)=m_{\mathrm{MX}}^{b} \cdot B_{\mathrm{MX}}$ and $B^{\prime}{ }_{\mathrm{MX}}$ describe the interaction of pairs of oppositely charged ions, which are defined as explicit functions of the ionic strength by:

$B_{\mathrm{MX}}=\beta_{\mathrm{MX}}^{0}+\beta_{\mathrm{MX}}^{1} g\left(x_{1}\right)+\beta_{\mathrm{MX}}^{2} g\left(x_{2}\right)$,

$x_{1}=\alpha_{1} \sqrt{I} \quad x_{2}=\alpha_{2} \sqrt{I}$,

$g(x)=2\left[1-(1+x) e^{-x}\right] / x^{2}$

$B_{\mathrm{MX}}^{\prime}=\beta_{\mathrm{MX}}^{1} g^{\prime}\left(x_{1}\right) / I+\beta_{\mathrm{MX}}^{2} g^{\prime}\left(x_{2}\right) / I$,

$g^{\prime}(x)=-2\left[1-\left(1+x+0.5 x^{2}\right) e^{-x}\right] / x^{2}$,

where $\beta_{\mathrm{MX}}^{0}, \beta_{\mathrm{MX}}^{1}, \beta_{\mathrm{MX}}^{2}$ are the Pitzer parameters, and $\alpha_{1}=2$ for $1: 1$ electrolytes $\left(\alpha_{2}=0\right.$, except for $\mathrm{HNO}_{3}, \alpha_{2}=1$, Christov, 2005). The term $C_{\mathrm{MX}}$ describes ternary short range interactions between two cations and one anion, and one cation and two anions. It is expressed by:

$C_{\mathrm{MX}}=0.5 C_{\mathrm{MX}}^{\phi}$

We, therefore, need four coefficient values, $\beta_{\mathrm{MX}}^{0}, \beta_{\mathrm{MX}}^{1}, \beta_{\mathrm{MX}}^{2}$ and $C_{\mathrm{MX}}^{\phi}$, to predict the activity coefficient using the Pitzer theory for 1:1 electrolytes. These values are available in Pitzer databases for many electrolytes (Pitzer, 1973; Pitzer and Mayorga, 1973; Harvie and Weare, 1980; Harvie et al., 1984; Plummer et al., 1988; Felmy et al., 1994; Pitzer, 1995; 
Christov and Moller, 2004; Carroll et al., 2005; Christov, 2005; see Table 1 for the electrolytes investigated in our study). In the case of $\mathrm{HCl}$ and $\mathrm{HNO}_{3}$ electrolytes, we use a methodology for determining Pitzer interaction parameters. This methodology is based on the use of PEST (Doherty, 1994), a nonlinear parameter estimation and optimization package, coupled to the PHREEQC code (Parkhurst and Appelo, 1999). PEST takes control of PHREEQC, running it as many times as necessary while adjusting the Pitzer interaction parameters. The fitting procedure stops when the discrepancies between selected model outputs and a complementary set of field or laboratory measurements are reduced to a minimum. The computations were performed using measurements of water activities and mineral solubilities (Hamer and $\mathrm{Wu}, 1972$ ). 


\section{APPENDIX B}

The following set of equations describes the variation of the mean activity coefficient for 1:1 electrolytes with the molality (the superscript " $b$ " has been deleted for clarity):

$$
\begin{aligned}
& \frac{d \ln \gamma_{\mathrm{MX}}}{d m_{\mathrm{MX}}}=\frac{d \ln \gamma_{\mathrm{MX}}}{d I} \times \frac{d I}{d m_{\mathrm{MX}}}=\frac{d \ln \gamma_{\mathrm{MX}}}{d I}, \\
& \frac{d \ln \gamma_{\mathrm{MX}}}{d I}=\frac{d F}{d I}+2 B_{\mathrm{MX}}+2 I\left(\frac{d B_{\mathrm{MX}}}{d I}+3 C_{\mathrm{MX}}\right), \\
& \frac{d F}{d I}=-\frac{A^{\phi}}{2}\left[\frac{3 I^{-1 / 2}(1+b \sqrt{I})-b}{(1+b \sqrt{I})^{2}}\right]+2 I B_{\mathrm{MX}}^{\prime}+I^{2} \frac{d B_{\mathrm{MX}}^{\prime}}{d I}, \\
& \frac{d B_{\mathrm{MX}}}{d I}=\sum_{i=1}^{2} \frac{\alpha_{i} \beta_{\mathrm{MX}}^{i}}{2 \sqrt{I}}\left[-\frac{2}{x_{i}} g\left(x_{i}\right)+\frac{2}{x_{i}} e^{-x_{i}}\right], \\
& \frac{d B_{\mathrm{MX}}^{\prime}}{d I}=\sum_{i=1}^{2} \frac{\beta_{\mathrm{MX}}^{i}}{I^{2}}\left\{\frac{\alpha_{i} \sqrt{I}}{2}\left[-\frac{2}{x_{i}} g^{\prime}\left(x_{i}\right)-e^{-x_{i}}\right]-g^{\prime}\left(x_{i}\right)\right\} .
\end{aligned}
$$




\section{APPENDIX C}

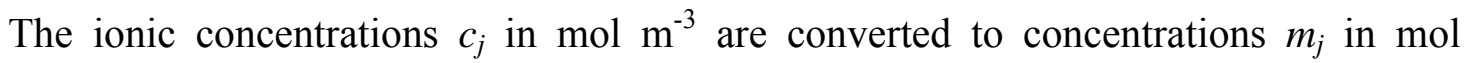
$\mathrm{kg}_{\text {water }}{ }^{-1}$ by:

$$
\begin{aligned}
& m_{j}=\frac{1000 c_{j}}{M_{w} c_{w}}, \\
& c_{w}=\left[10^{6}-\left(c_{\mathrm{M}} V_{\mathrm{M} m}+c_{\mathrm{X}} V_{\mathrm{X} m}\right)\right] / V_{w m},
\end{aligned}
$$

where $M_{w}$ is the molar mass of water (in $\mathrm{g} \mathrm{mol}^{-1}$ ), $c_{w}$ the concentration of water (in $\mathrm{mol} \mathrm{m} \mathrm{m}^{-3}$ ), and $V_{i m}$ the standard partial molal volume $\left(\right.$ in $\mathrm{cm}^{3} \mathrm{~mol}^{-1}$ ) of the species. 


\section{REFERENCES}

Abramzon A. A. and Gaukhberg R. D. (1993) Surface tension of salt solutions. Russian J. Appl. Chem. 66 (6), 1139-1146; 66 (7), 1315-1320; 66 (8), 1473-1479; and 66 (9), 16431650.

André L., Audigane P., Azaroual M. and Menjoz A. (2007) Numerical modeling of fluid-rock chemical interactions at the supercritical $\mathrm{CO}_{2}$-liquid interface during $\mathrm{CO}_{2}$ injection into a carbonate reservoir, the Dogger aquifer (Paris Basin, France). Energy Conversion and Management 48, 1782-1797.

Azaroual M., Fouillac C. and Matray J. M. (1997) Solubility of silica polymorphs in electrolyte solutions, I. Activity coefficient of aqueous silica from $25^{\circ}$ to $250^{\circ} \mathrm{C}$, Pitzer's parameterisation. Chemical Geology 140 (3-4), 155-165.

Azaroual M., Kervévan C., Durance M. N. and Durst P. (2004) SCALE2000: reactiontransport software dedicated to thermokinetic prediction and quantification of scales applicability to desalination problems. Desalination 165 (15), 409-419.

Bhuiyan L. B., Bratko O. and Outhwaite C. W. (1991) Electrolyte surface-tension in the modified Poisson-Boltzmann approximation. J. Phys. Chem. 95, 336-340.

Bhuiyan L. B., Bratko O. and Outhwaite C. W. (1992) Structure and thermodynamics of micellar solutions in the modified Poisson-Boltzmann theory. Chem. Phys. Lett. 193 (4), $203-210$

Boström M., Williams D. M. R. and Ninham B. W. (2001) Surface tension of electrolytes: Specific ion effects explained by dispersion forces. Langmuir 17 (15), 4475-4478. 
Boström M., Kunz W. and Ninham B. W. (2005) Hofmeister effects in surface tension of aqueous electrolyte solution. Langmuir 21 (6), 2619-2623.

Brown M. A., Winter B., Faubel M. and Hemminger J. C. (2009) Spatial distribution of nitrate and nitrite anions at the liquid/vapor interface of aqueous solutions. J. Am. Chem. Soc. 131 (24), 8354-8355.

Caceci M. and Cacheris W. P. (1984) Fitting curves to data. The simplex algorithm is the answer. Byte 9, 340-362.

Carroll S., Craig L. and Wolery T. J. (2005) Deliquescence of NaCl-NaNO3, KNO3-NaNO3, and $\mathrm{NaCl}-\mathrm{KNO} 3$ salt mixtures from 90 to $120^{\circ} \mathrm{C}$. Geochem. Trans. 6 (2), 19-30, doi: $10.1186 / 1467-4866-6-19$.

Chapman D. L. (1913) A contribution to the theory of electrocapillarity. Philosophical Magazine 25, 475-481.

Chiquet P., Daridon J. -L., Broseta D. and Thibeau S. (2007) $\mathrm{CO}_{2} /$ water interfacial tensions under pressure and temperature conditions of $\mathrm{CO}_{2}$ geological storage. Energy Conversion and Management 48, 736-744.

Christov C. and Moller N. (2004) Chemical equilibrium model of solution behavior and solubility in the $\mathrm{H}-\mathrm{Na}-\mathrm{K}-\mathrm{OH}-\mathrm{Cl}-\mathrm{HSO}_{4}-\mathrm{SO}_{4}-\mathrm{H}_{2} \mathrm{O}$ system to high concentration and temperature. Geochim. Cosmochim. Acta 68 (6), 1309-1331.

Christov C. (2005) Thermodynamics of formation of double salts and mixed crystals from aqueous solutions. J. Chem. Thermodyn. 37 (10), 1036-1060.

Collins K. D. and Washabaugh M. W. (1985) The Hofmeister effect and the behavior of water at interfaces. Quarterly Reviews of Biophysics 18, 323-422. 
Dang L. X., Chang T. M., Roeselova M., Garrett B. C. and Tobias D. J. (2006) On $\mathrm{NO}_{3}-\mathrm{H}_{2} \mathrm{O}$ interactions in aqueous solutions and at interfaces. J. Chem. Phys. 124 (6), 06610110661013.

Desnoyer C., Masbernat O. and Gourdon C. (1997) Predictive model for the calculation of interfacial tension in nonideal electrolytic systems. J. Colloid Interface Sci. 191 (1), 2229.

Doherty J. (1994) PEST: Model-Independent Parameter Estimation, User Manual: $5^{\text {th }}$ Edition, Watermark Numerical Computing, Brisbane, Australia.

Douillard J. M. and Médout-Marère V. (2000) A new interpretation of contact angle variations in view of a recent analysis of immersion calorimetry. J. Colloid Interface Sci. $223(2), 255-260$.

Felmy A. R., Schroeder C. C. and Mason J. M. (1994) A solubility model for amorphous silica in concentrated electrolytes. Symposium of Scientific Issues Related to Safety and Treatment of Hanford Waste Tanks, Washington D.C.

Forsman J. (2009) Density functional theory of surface interactions in salt solutions. J. Chem. Phys. 130, 064901-064913.

Gouy G. (1910) Sur la constitution de la charge électrique à la surface d'un électrolyte. Journal de Physique Théorique Appliquée 4 (9), 457-468.

Guggenheim E. A. and Adam N. K. (1933) The thermodynamics of adsorption at the surface of solutions. Proc. R. Soc., London, 139A, 218-236.

Hamer W. J. and Wu Y -C. (1972) Osmotic coefficients and mean activity coefficients of uniunivalent electrolytes in water at $25^{\circ} \mathrm{C}$. J. Phys. Chem. Ref. Data 1 (4), 1047-1075. 
Harvie C. E. and Weare J. H. (1980) The prediction of mineral solubilities in natural waters: the Na-K-Mg-Ca-Cl-SO $\mathrm{S}_{4}-\mathrm{H}_{2} \mathrm{O}$ system from zero to high concentration at $25^{\circ} \mathrm{C}$. Geochim. Cosmochim. Acta 44 (7), 981-997.

Harvie C. E., Moller N. and Weare J. H. (1984) The prediction of mineral solubilities in natural waters: The Na-K-Mg-Ca-H-Cl-SO $\mathrm{S}_{4}-\mathrm{OH}-\mathrm{HCO}_{3}-\mathrm{CO}_{3}-\mathrm{CO}_{2}-\mathrm{H}_{2} \mathrm{O}$ system to high ionic strengths at $25^{\circ} \mathrm{C}$. Geochim. Cosmochim. Acta 48 (4), 723-751.

Helgeson H. C., Kirkham D. H. and Flowers G. C. (1981) Theoretical prediction of the thermodynamic behavior of aqueous electrolytes at high pressures and temperatures. IV Calculation of activity coefficients, osmotic coefficients and apparent molal and standard and relative molal properties to $600{ }^{\circ} \mathrm{C}$ and 5 kbar. Amer. J. Sci. 281, 1241-1516.

Henry E. J., Smith J. E. and Warrick A. W. (2001) Surfactant effects on unsaturated flow in porous media with hysteresis: horizontal column experiments and numerical modeling. $J$. Hydr. 245 (1-4), 73-88.

Hey M. J., Shield D. W., Speight J. M. and Will M. C. (1981) Surface tensions of aqueous solutions of some 1:1 electrolytes. J. Chem. Soc., Faraday Trans. 1 (77), 123-131.

Horne R. A. and Young R. P. (1972) Cation exclusion by interfacial water structure. Electrochim. Acta 17 (4), 763-767.

Hribar B., Southall N. T., Vlachy V. and Dill K. A. (2002) How ions affect the structure of water. J. Am. Chem. Soc. 124 (41), 12302-12311.

Hunter R. J. (1981) Zeta potential in colloid science: Principles and applications. Academic Press, London, 386 pp. 
Jungwirth P. and Tobias D. J. (2001) Molecular structure of salt solutions: a new view of the interface with implications for heterogeneous atmospheric chemistry. J. Phys. Chem. 105, 10468-10472.

Jungwirth P. and Tobias D. J. (2006) Specific ion effects at the air/water interface. Chem. Rev. 106 (4), 1259-1281.

Karraker K. A. and Radke C. J. (2002) Disjoining pressures, zeta potentials and surface tensions of aqueous non-ionic surfactant/electrolyte solutions: theory and comparison to experiment. Adv. Colloid Interface Sci. 96, 231-264.

Kralchevsky P. A. and Paunov V. N. (1992) Contribution of ionic correlations to excess free energy and disjoining pressure of thin liquid films 1 . Electric double layer inside the film. Colloids Surf. 64 (3-4), 245-264.

Lassin A., Azaroual M. and Mercury L. (2005) Geochemistry of unsaturated soil systems: aqueous speciation and solubility of minerals and gases in capillary solutions. Geochim. Cosmochim. Acta 69, 5187-5201.

Li Z. and Lu B. C. -Y. (2001) Surface tension of aqueous electrolyte solutions at high concentrations - representation and prediction. Chem. Eng. Sci. 5 (8), 2879-2888.

Li W. -K., Zhou G. D. and Mak T. C. W. (2008) Advanced Structural Inorganic Chemistry. Oxford University Press, 688 pp.

Lu J. -F., Yu Y. -X. and Li Y. -G. (1993) Modification and application of the mean spherical approximation method. Fluid Phase Eq. 85, 81-100.

Lyklema J. (1991) Fundamentals of Interface and Colloid Science, Volume I, Academic Press, London, 736 pp. 
Manciu M. and Ruckenstein E. (2003) Specific ion effects via ion hydration: I. Surface tension. Adv. Colloid Interface Sci. 105 (1-3), 63-101.

Manciu M. and Ruckenstein E. (2005) On the interactions of ions with the air/water interface. Langmuir 21 (24), 11312-11319.

Marcelja S. (2006) Selective coalescence of bubbles in simple electrolytes. J. Phys. Chem. B 110 (26), 13062-13067.

Marcus Y. (1987) Thermodynamics of ion hydration and its interpretation in terms of a common model. Pure Appl. Chem. 59 (9), 1093-1101.

Markin V. S. and Volkov A. G. (2002) Quantitative theory of surface tension and surface potential of aqueous solutions of electrolytes. J. Phys. Chem. B 106 (45), 11810-11817.

Mercury L., Azaroual M., Zeyen H. and Tardy Y. (2003) Thermodynamic properties of solutions in metastable systems under negative or positive pressure. Geochim. Cosmochim. Acta 67, 1769-1785.

Mucha M., Frigato T., Levering L. M., Allen H. C., Tobias D. J., Dang L. X. and Jungwirth P. (2005) Unified molecular picture of the surfaces of aqueous acid, base, and salt solutions. J. Phys. Chem. B 109 (16), 7617-7623.

Ninham B. W. and Yaminsky V. (1997) Ion binding and ion specificity: The Hofmeister Effect and Onsager and Lifshitz Theories. Langmuir 13 (7), 2097-2108.

Onsager L. and Samaras N. N. T. (1934) The surface tension of Debye-Hückel electrolytes. J. Phys. Chem. 2, 528-536. 
Parkhurst D. L. and Appelo C. A. J. (1999) User's guide to PHREEQC (version 2) - a computer program for speciation, reaction-path, 1D-transport, and inverse geochemical calculations. US Geological Survey Water Resources Investigations Report 99-4259, 312 pp.

Pegram L. M. and Record M. T. (2006) Partitioning of atmospherically relevant ions between bulk water and the water/vapor interface. Proceedings of the National Academy of Sciences 103 (39), 14278-14281.

Peng B. and Yu Y. -X. (2009) Ion distributions, exclusion coefficients, and separation factors of electrolytes in a charged cylindrical nanopore: A partially perturbative density functional theory study. J. Chem. Phys. 131 (13), 1347031-347037.

Pettenati M., Mercury L. and Azaroual M. (2008) Capillary geochemistry in non-saturated zone of soils. Water content and geochemical signatures. Appl. Geochem. 23, 3799-3818.

Pitzer K. S. (1973) Thermodynamics of electrolytes I. Theoretical basis and general equations. J. Phys. Chem. 77, 268-276.

Pitzer K. S. and Mayorga G. (1973) Thermodynamics of electrolytes II. Activity and osmotic coefficients with one or both ions univalent. J. Phys. Chem. 77, 2300-2308.

Pitzer K. S. (1995) Thermodynamics. Third Edition. Series in Advanced Chemistry, McGrawHill, New York, 626 pp.

Plummer L. N., Parkhurst D. L., Fleming G. W. and Dunkle S. A. (1988) A computer program incorporating Pitzer's equations for calculation of geochemical reactions in brines. USGS Report 88-4153, 33 pp. 
Prat M. (2007) On the influence of pore shape, contact angle and film flows on drying of capillary porous media. Int. J. Heat Mass Transfer 50 (7-8), 1455-1468.

Ralston J. and Healy T. W. (1973) Specific cation effects on water structure at the air-water and air-octadecanol monolayer-water interfaces. J. Colloid Interface Sci. 42, 629-644.

Salvador P., Curtis J. E., Tobias D. J. and Jungwirth P. (2003) Polarizability of the nitrate anion and its solvation at the air/water interface. Phys. Chem. Chem. Phys. 5 (17), 37523757.

Shock E. L. and Helgeson H. C. (1988) Calculation of the thermodynamic and transport properties of aqueous species at high temperatures: Correlation algorithms for ionic species and equation of state predictions to $5 \mathrm{~Kb}$ and $1000^{\circ} \mathrm{C}$. Geochim. Cosmochim. Acta 52, 2009-2036.

Sghaier N., Prat M. and Ben Nasrallah S. (2006) On the influence of sodium chloride concentration on equilibrium contact angle. Chem. Eng. J. 122 (1-2), 47-53.

Smith J. E. and Gillham R. W. (1999) Effects of solute concentration-dependent surface tension on unsaturated flow: Laboratory sand column experiments. Water Resour. Res. 35 (4), 973-982.

Sverjensky D. A. (2006) Prediction of the speciation of alkaline earths adsorbed on mineral surfaces in salt solution. Geochim. Cosmochim. Acta 70, 2427-2453.

Tanger J. C. IV and Helgeson H. C. (1988) Calculation of the thermodynamic and transport properties of aqueous species at high pressures and temperatures: Revised equations of state for the standard partial molal properties of ions and electrolytes. Am. J. Sci. 288, 1998 
Thomas J. L., Roeselova M., Dang L. X. and Tobias D. J. (2007) Molecular dynamics simulations of the solution-air interface of aqueous sodium nitrate. J. Phys. Chem. A 111, 3091-3098.

Ward C. A. and Sefiane K. (2009) Adsorption at the solid-liquid interface as the source of contact angle dependence on the curvature of the three-phase line. Adv. Colloid Interface Sci., In Press, Corrected Proof.

Weissenborn P. K. and Pugh R. J. (1996) Surface tension of aqueous solutions of electrolytes: Relationship with ion hydration, oxygen solubility, and bubble coalescence. J. Colloid Interface Sci. 184 (2), 550-563.

Yu Y. -X., Gao G. -H., and Li Y. -G. (2000) Surface tension for aqueous electrolyte solutions by the modified mean spherical approximation. Fluid Phase Eq. 173 (1), 23-38. 
Table 1. Pitzer parameters used in this study

\begin{tabular}{lccccc}
\hline Solutions & $\beta_{\mathrm{MX}}^{0}$ & $\beta_{\mathrm{MX}}^{1}$ & $\beta_{\mathrm{MX}}^{2}$ & $C_{\mathrm{MX}}^{\phi}$ & $m_{\max }^{b}$ \\
\hline $\mathrm{NaCl}^{\mathrm{a}}\left(25^{\circ} \mathrm{C}\right)$ & 0.0765 & 0.2644 & 0 & $1.27 \times 10^{-3}$ & $5.50^{* *}$ \\
$\mathrm{KCl}^{\mathrm{a}}\left(25^{\circ} \mathrm{C}\right)$ & 0.04835 & 0.2122 & 0 & $-8.40 \times 10^{-4}$ & $3.35^{* *}$ \\
$\mathrm{HCl}^{\mathrm{c}}\left(25^{\circ} \mathrm{C}\right)$ & 0.1973 & 0.1691 & 0 & $-3.175 \times 10^{-3}$ & $14.98^{* *}$ \\
$\mathrm{NaNO}_{3}{ }^{\mathrm{b}}\left(20^{\circ} \mathrm{C}\right)$ & $1.443 \times 10^{-3}$ & 0.1861 & 0 & $1.212 \times 10^{-4}$ & $9.84^{* *}$ \\
$\mathrm{KNO}_{3}{ }^{\mathrm{d}}\left(25^{\circ} \mathrm{C}\right)$ & 0.0816 & 0.0494 & 0 & $6.60 \times 10^{-3}$ & $2.63^{* *}$ \\
$\mathrm{HNO}_{3}{ }^{\mathrm{e}}\left(25^{\circ} \mathrm{C}\right)^{*}$ & -0.1560 & 0.2847 & 0.3083 & $-4.006 \times 10^{-7}$ & $29.09^{* *}$ \\
\hline
\end{tabular}

${ }^{a}$ Pitzer and Mayorga (1973)

${ }^{\mathrm{b}}$ Felmy et al. (1994)

${ }^{\mathrm{c}}$ by ajusting the Pitzer parameters

${ }^{\mathrm{d}}$ Carroll et al. (2005)

${ }^{\mathrm{e}}$ by ajusting the Pitzer parameters

* In the case of $\mathrm{HNO}_{3}$, we need a four parameters parametrization to predict correctly the activity coefficients $\left(\alpha_{1}=2, \alpha_{2}=0.1\right)$.

** The $m_{\max }^{b}$ values are given by Li and Lu (2001). 
Table 2. Standard partial molal volumes of the species calculated with the "Thermo-ZNS" computer code (Lassin et al., 2005)

\begin{tabular}{lcc}
\hline \multirow{2}{*}{ Species } & \multicolumn{2}{c}{ Volume $\left(\mathrm{cm}^{3} \mathrm{~mol}^{-1}\right)$} \\
\cline { 2 - 3 } & $T=20^{\circ} \mathrm{C}$ & $T=25^{\circ} \mathrm{C}$ \\
\hline $\mathrm{H}_{2} \mathrm{O}$ & 18.05 & 18.07 \\
$\mathrm{H}^{+}$ & 0.00 & 0.00 \\
$\mathrm{Na}^{+}$ & -1.44 & -1.13 \\
$\mathrm{~K}^{+}$ & 8.84 & 9.05 \\
$\mathrm{Cl}^{-}$ & 17.54 & 17.68 \\
$\mathrm{NO}_{3}^{-}$ & 28.25 & 28.92 \\
\hline
\end{tabular}


Table 3. Ionic and effective electrostatic radii of the species $\left(T=25^{\circ} \mathrm{C}\right)$

\begin{tabular}{lcc}
\hline Ions & Ionic radius $(\AA)$ & Electrostatic radius $(\AA)$ \\
\hline $\mathrm{H}^{+}\left(\mathrm{H}_{3} \mathrm{O}^{+}\right)$ & $2.14^{\mathrm{a}}$ & $3.08^{\mathrm{a}}$ \\
$\mathrm{Na}^{+}$ & $0.97^{\mathrm{c}} 1.02^{\mathrm{b}}$ & $1.91^{\mathrm{c}} 2.18^{\mathrm{b}}$ \\
$\mathrm{K}^{+}$ & $1.33^{\mathrm{c}} 1.38^{\mathrm{b}}$ & $2.13^{\mathrm{b}} 2.27^{\mathrm{c}}$ \\
$\mathrm{Cl}^{-}$ & $1.81^{\mathrm{c}}$ & $1.81^{\mathrm{c}}$ \\
$\mathrm{NO}_{3}{ }^{-}$ & $2.81^{\mathrm{a}}$ & $2.81^{\mathrm{a}} 2.97^{\mathrm{c}}$ \\
\hline
\end{tabular}

${ }^{\mathrm{a}}$ Helgeson et al. (1981)

${ }^{\mathrm{b}}$ Marcus (1987)

${ }^{\mathrm{c}}$ Shock and Helgeson (1988) 
Table 4. Optimized parameter values for the distance $d$ and the interaction free energy $W$

\begin{tabular}{lccccc} 
& $\mathrm{Na}^{+}$ & $\mathrm{K}^{+}$ & $\mathrm{H}^{+}$ & $\mathrm{Cl}^{-}$ & $\mathrm{NO}_{3}^{-}$ \\
\hline$d(\AA)$ & $4.25 \pm 1$ & $4.5 \pm 1$ & $6.2 \pm 2$ & $1 \pm 0.5$ & 0 \\
$W\left(k_{b} T\right)$ & $\infty$ & $\infty$ & $-0.3 \pm 0.1$ & $\infty$ & $\infty$ \\
\hline
\end{tabular}




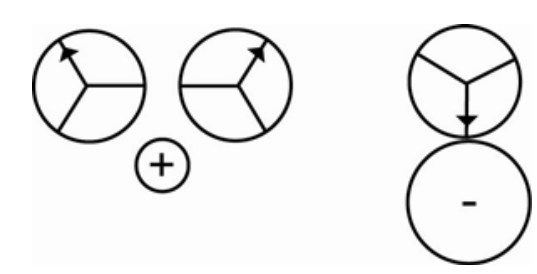

Figure 1. Schematic representation of the structure-making and structure-breaking ions (from Hribar et al., 2002). Structure-making ions (like $\mathrm{Na}^{+}$) promote hydrogen bonding of neighbouring waters. Structure-breaking ions (like $\mathrm{I}^{-}$) promote interaction with the neighbouring waters. 


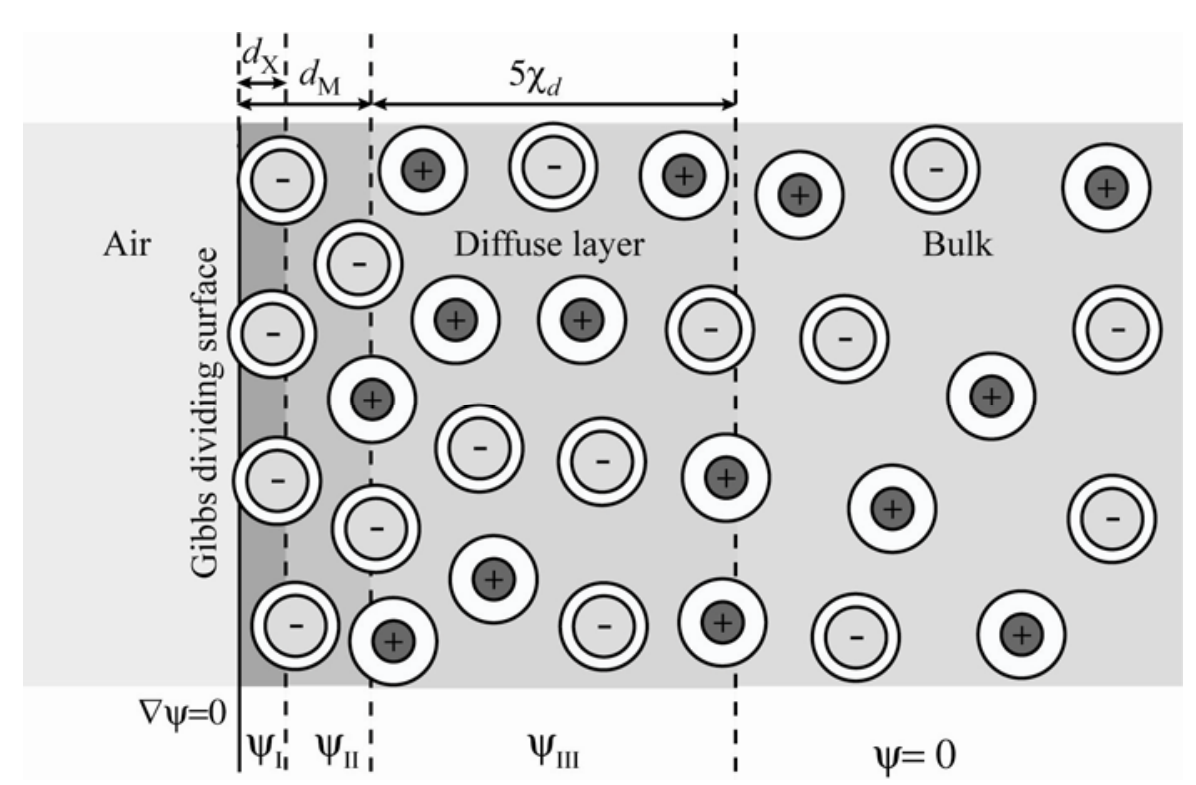

Figure 2. The distribution of ionic species at the air/water interface according to the approach of Manciu and Ruckenstein (2003) (for 1:1 electrolytes). Structure-making ions (cations here, $W_{\mathrm{M}}>0$ ) can better organize the water dipoles in bulk water than at the interface. The structurebreaking ions, on the other hand, are pushed toward the interface by the bulk water $\left(W_{\mathrm{X}}<0\right)$ because the bulk water molecules can better organize their hydrogen bonding network without these ions. The thicknesses of the interface layers are exaggerated compared to the size of the ions. 

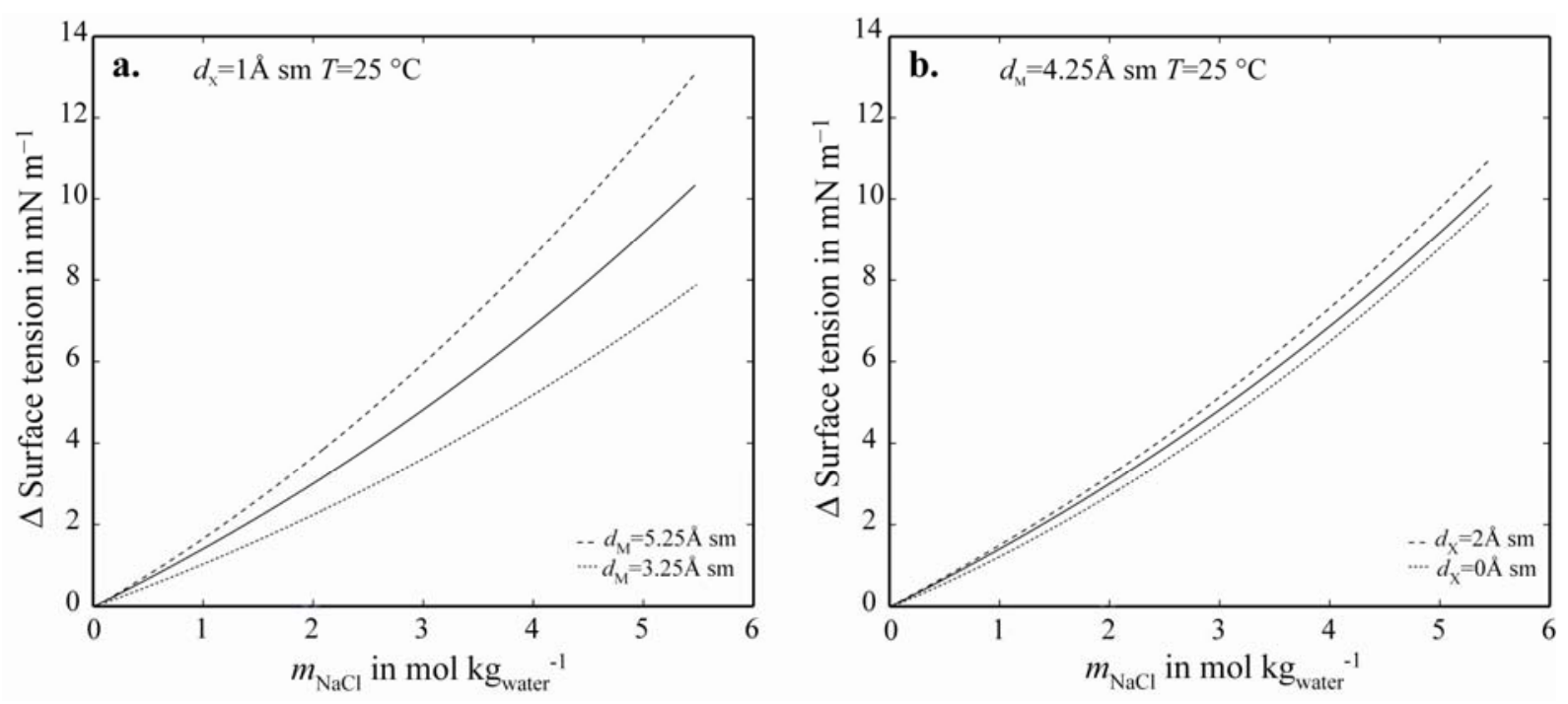

Figure 3. Sensitivity analysis for the prediction of the surface tension of an aqueous $\mathrm{NaCl}$ solution (sm: structure-making). The solid lines are the model calculations using $d_{\mathrm{X}}=1 \AA$ and $d_{\mathrm{M}}=4 \AA$. 


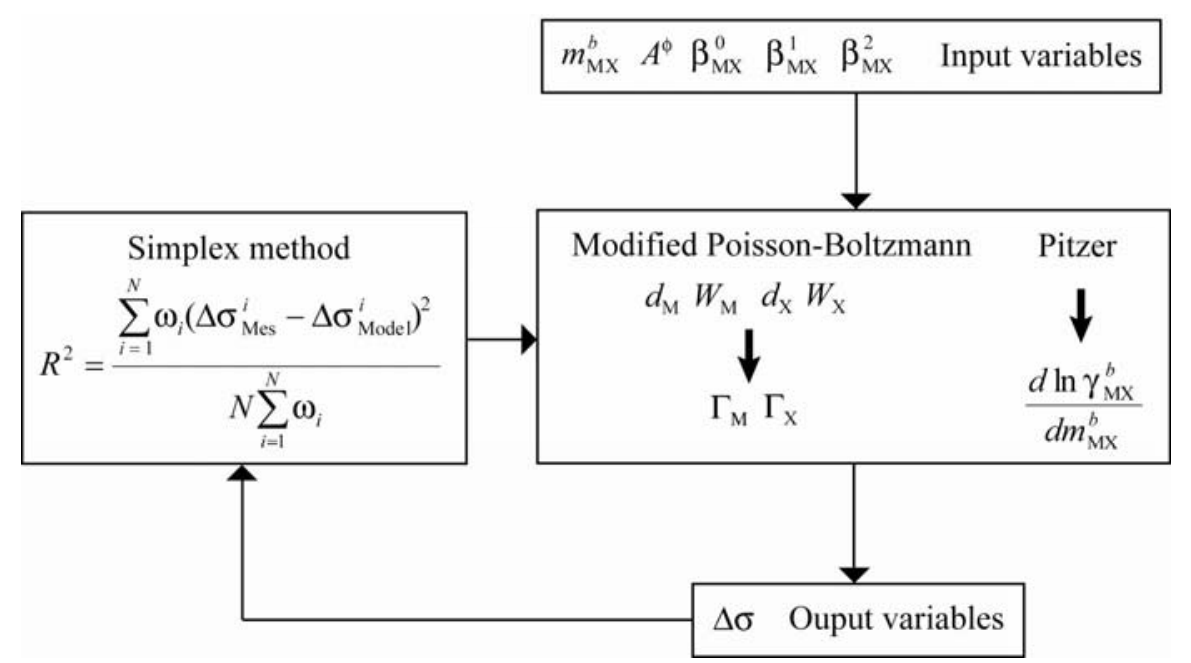

Figure 4. The optimization procedure used to determine the value of $d$ and $W$ for each ionic species. The Simplex algorithm is used to minimize the cost function $R^{2}$. The parameters $\omega_{i}$ are the weight coefficients. By default, $\omega_{i}=1$. 

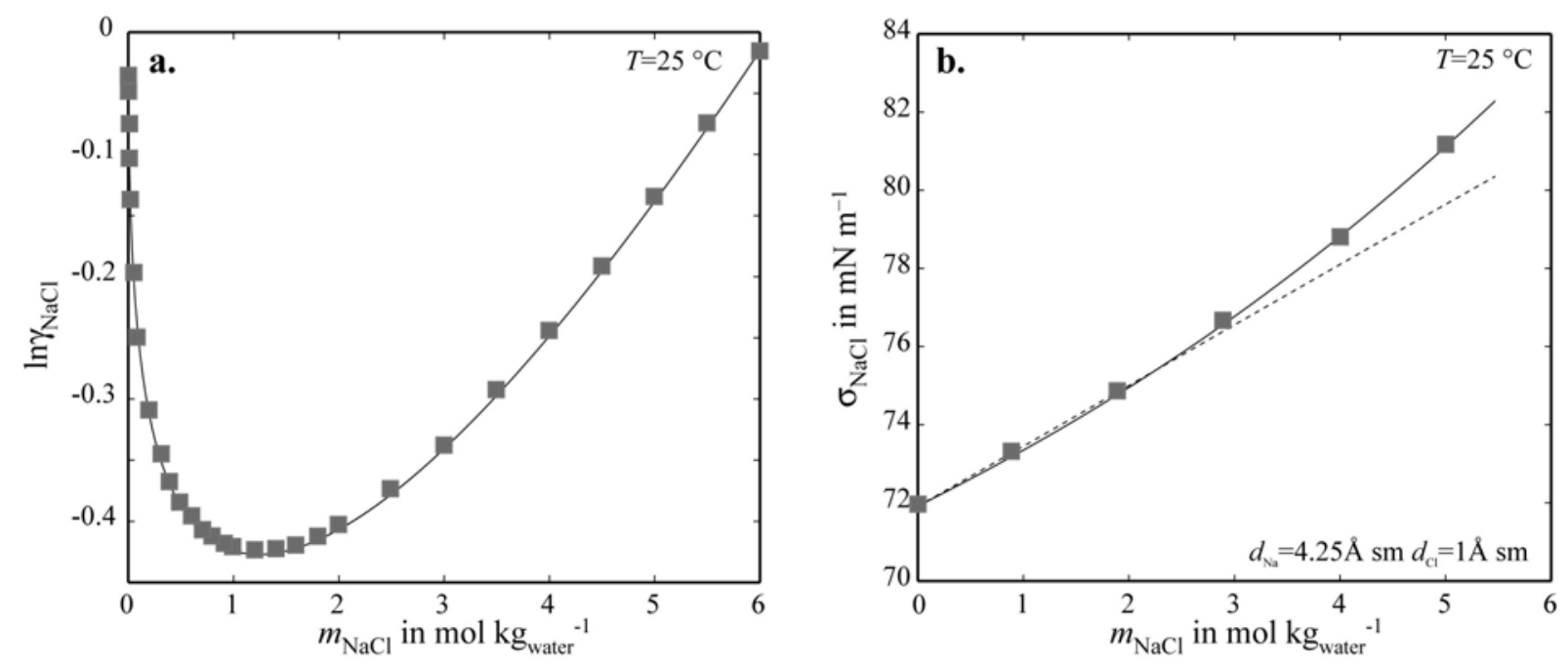

Figure 5. The surface tension (a) and mean activity coefficient (b) of an aqueous $\mathrm{NaCl}$ solution versus its molality in the bulk water ("sm": structure-making). The uncertainties are smaller than the size of the symbols. Symbols correspond to the experimental data of Hamer and $\mathrm{Wu}$ (1972) for the activity coefficients and of Abramzon and Gaukhberg (1993) for the surface tension. Plain lines correspond to the model predictions and dashed line to the predictions with $\gamma_{\mathrm{MX}}=1$. 


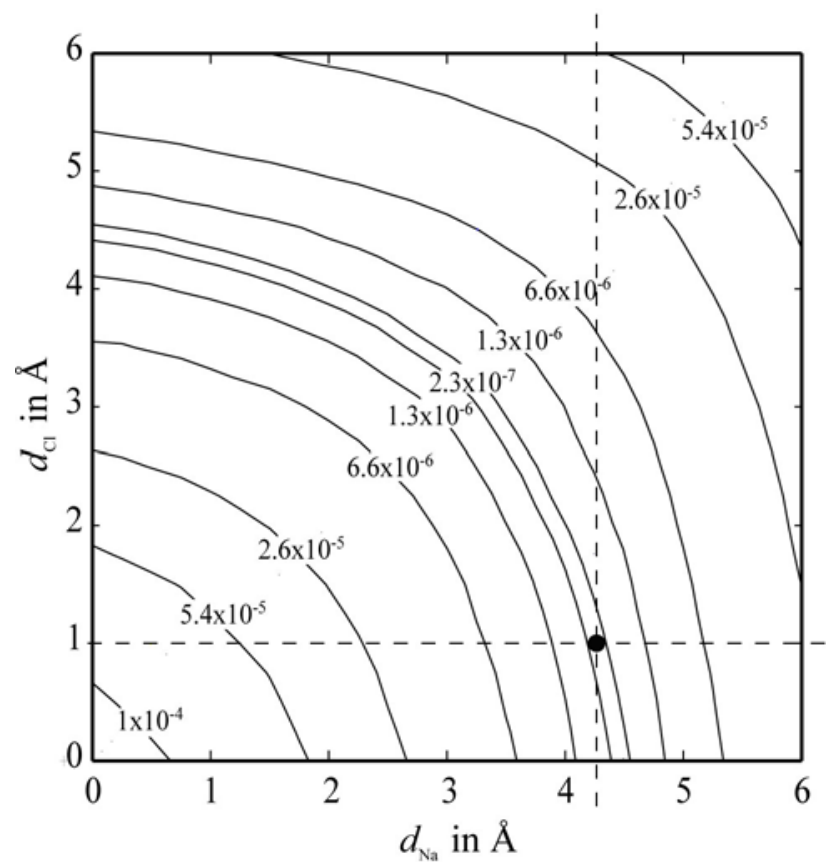

Figure 6. Shape of the cost function $R^{2}$ in the case of the $\mathrm{NaCl}$ electrolyte surface tension. This function has a unique minimum corresponding to the position of the filled circle. The optimized value of $d_{\mathrm{Na}}(4.25 \AA)$ is very close to the value of its mean effective electrostatic diameter (4.09 $\AA$, using an arithmetic mean of the values of Marcus, 1987 and Shock and Helgeson, 1988; see Table 3). 

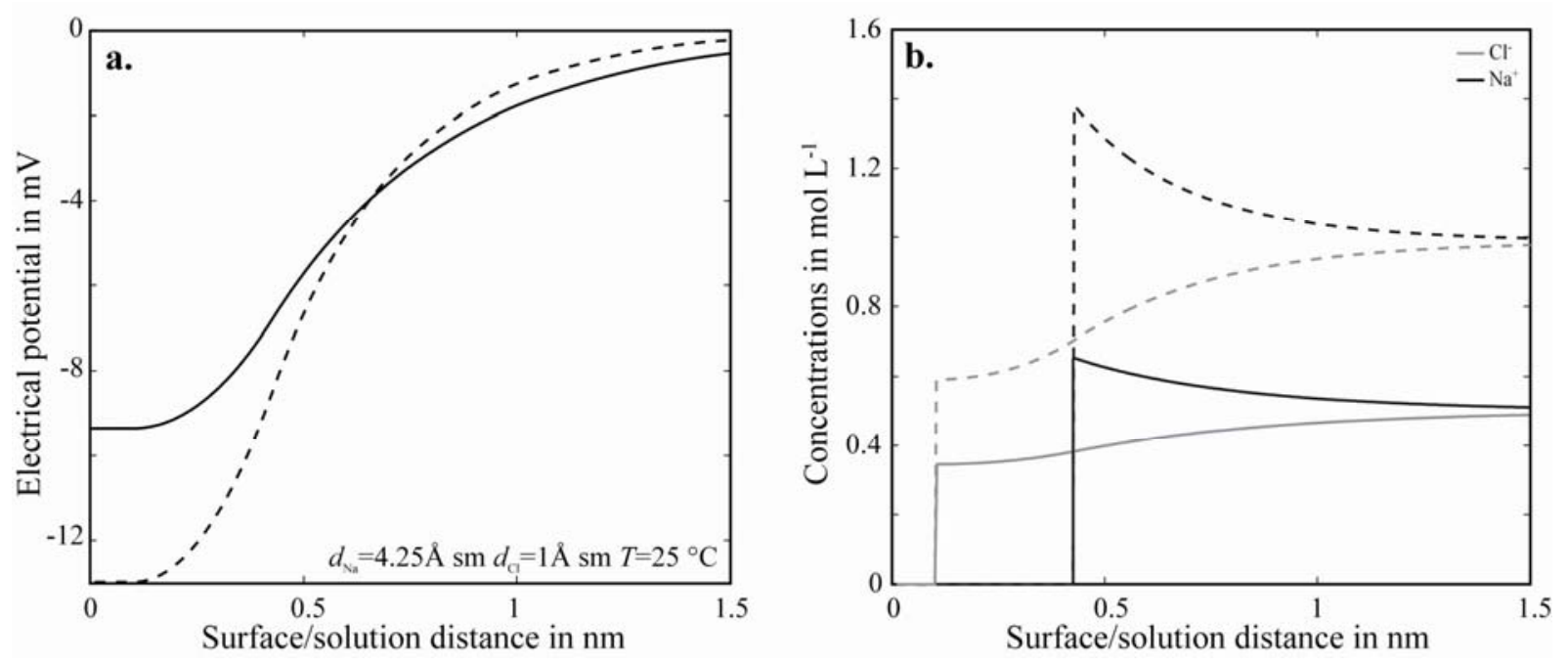

Figure 7. Electrical potential at the air/water interface from the model in the case of $\mathrm{NaCl}$ electrolytes using the parameters described in Fig. 5a (a) and the corresponding concentration profiles of chlorides and sodiums (b) (the plain and dashed line correspond to a molarity of 0.5 and $1 \mathrm{~mol} \mathrm{~L}^{-1}$, respectively). The deficit of ionic species at interface are responsible for the observed surface tension at the air/water interface. 


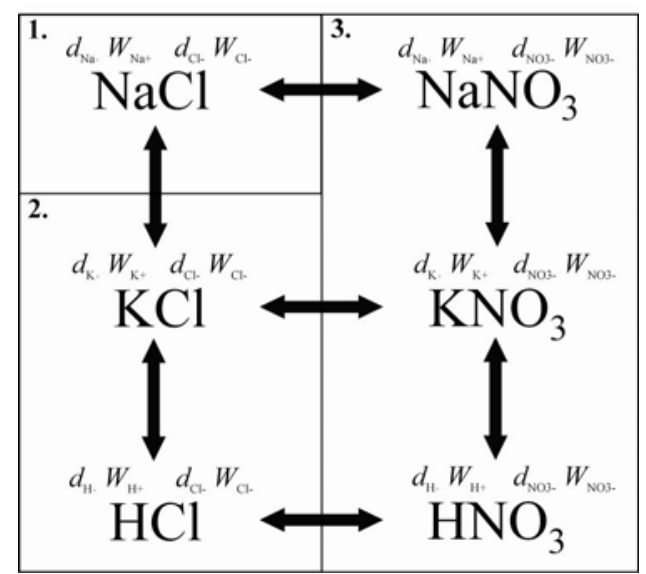

Figure 8. The optimization procedure used to determine the value of $d$ and $W$ for each ionic species and for different electrolytes. At first, the Simplex algorithm is used to optimize the values of $d$ and $W$ for $\mathrm{NaCl}$-electrolyte. Secondly, the optimized values of $d_{\mathrm{Cl}}$ and $W_{\mathrm{Cl}}$ are utilized to constrain the parameter values for $\mathrm{KCl}$ and $\mathrm{HCl}$ electrolytes. The gradient descent method is used to optimize $d_{\mathrm{K}+}$ and the Simplex to estimate $d_{\mathrm{H}+}$ and $W_{\mathrm{H}^{+}}$. Thirdly, the optimized value of $d_{\mathrm{Na}}$ constrains the parameter values for $\mathrm{NaNO}_{3}$ electrolyte. Finally, all the optimized parameter values for $\mathrm{K}^{+}, \mathrm{H}^{+}$, and $\mathrm{NO}_{3}{ }^{-}$are used to predict the surface tension variation for $\mathrm{KNO}_{3}$ and $\mathrm{HNO}_{3}$ electrolytes. 

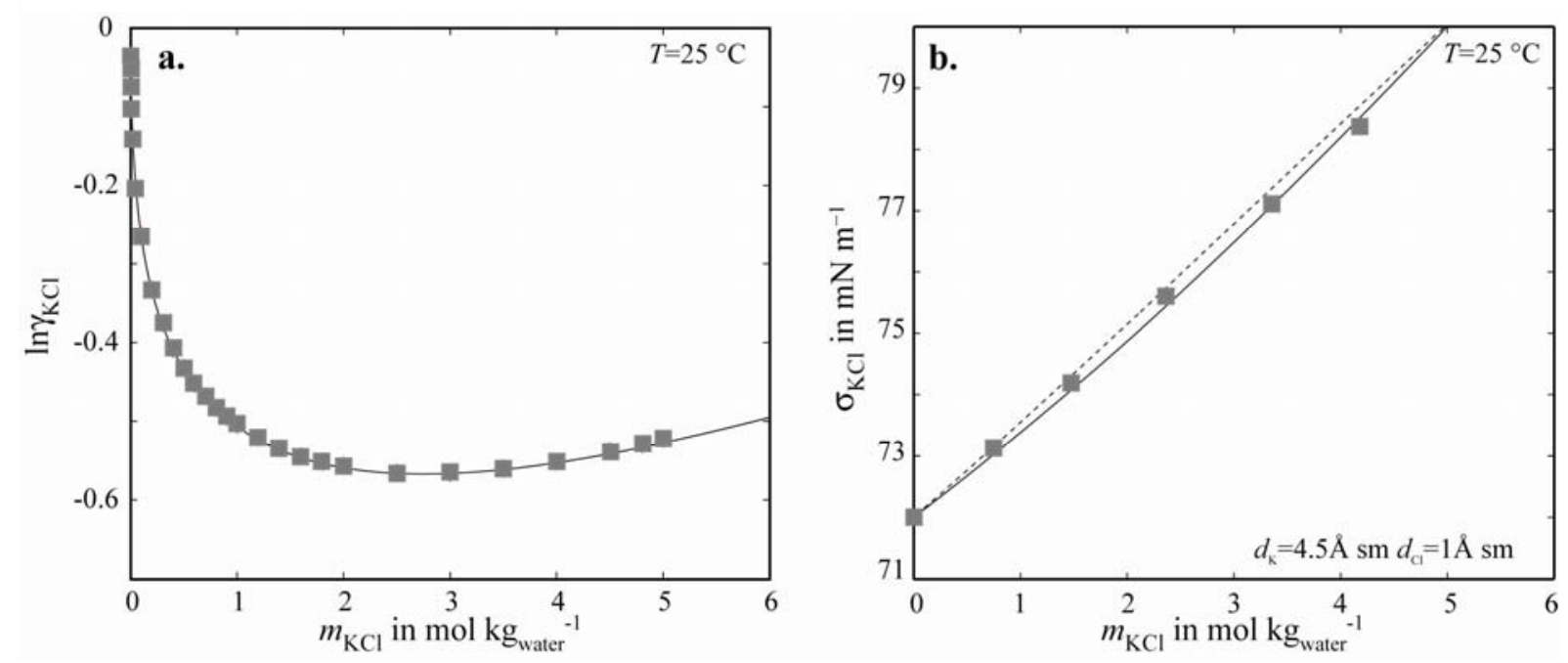

Figure 9. The surface tension (a) and mean activity coefficient (b) of an aqueous $\mathrm{KCl}$ solution versus its molality in the bulk water. 

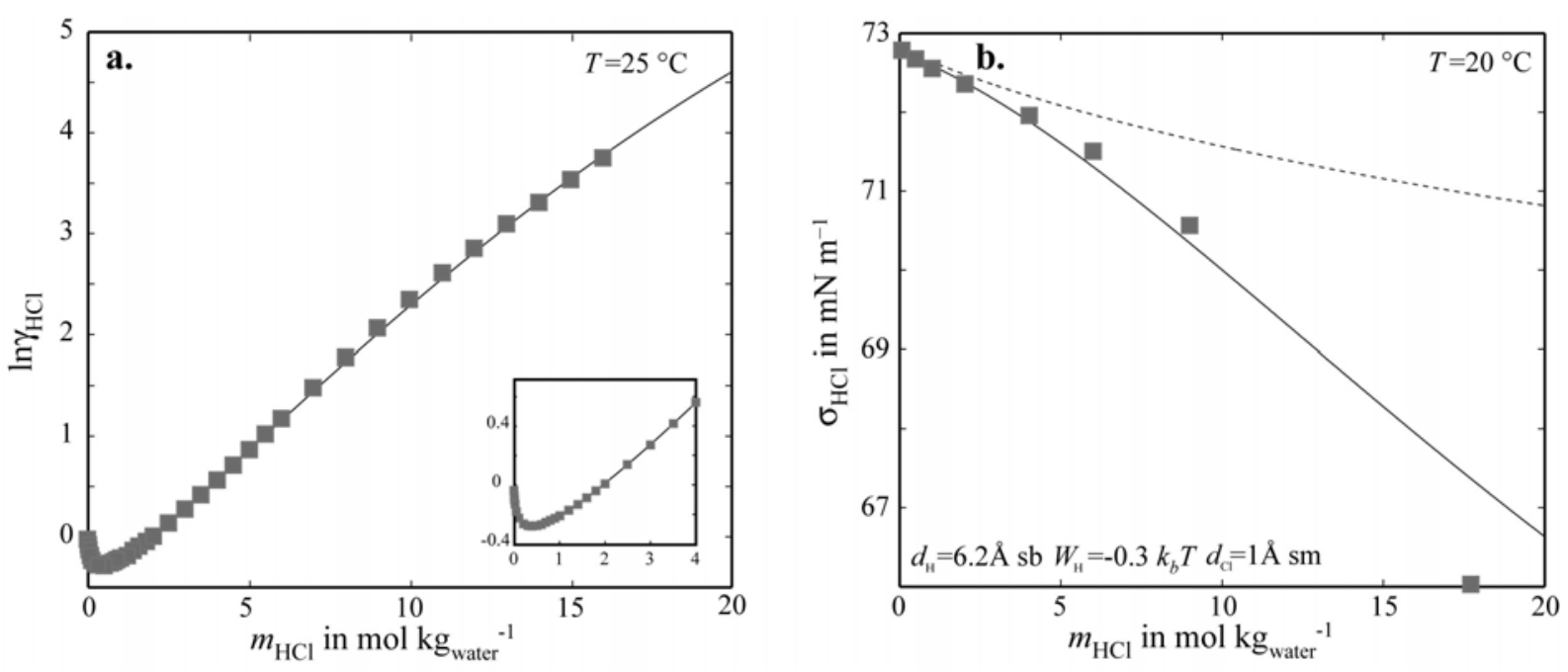

Figure 10. The surface tension (a) and mean activity coefficient (b) of an aqueous $\mathrm{HCl}$ solution versus its molality in the bulk water ("sm": structure-making; "sb": structurebreaking). 

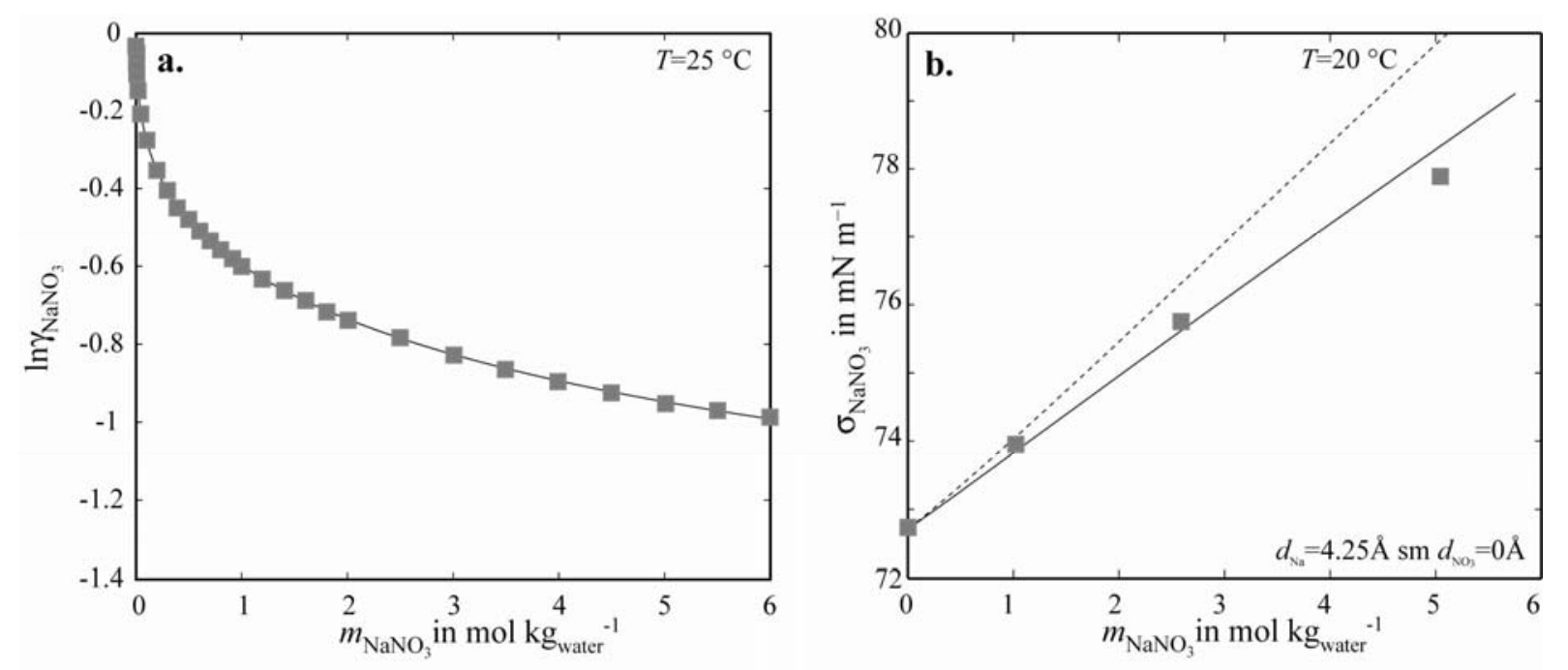

Figure 11. The surface tension (a) and mean activity coefficient (b) of an aqueous $\mathrm{NaNO}_{3}$ solution versus its molality in the bulk water. 

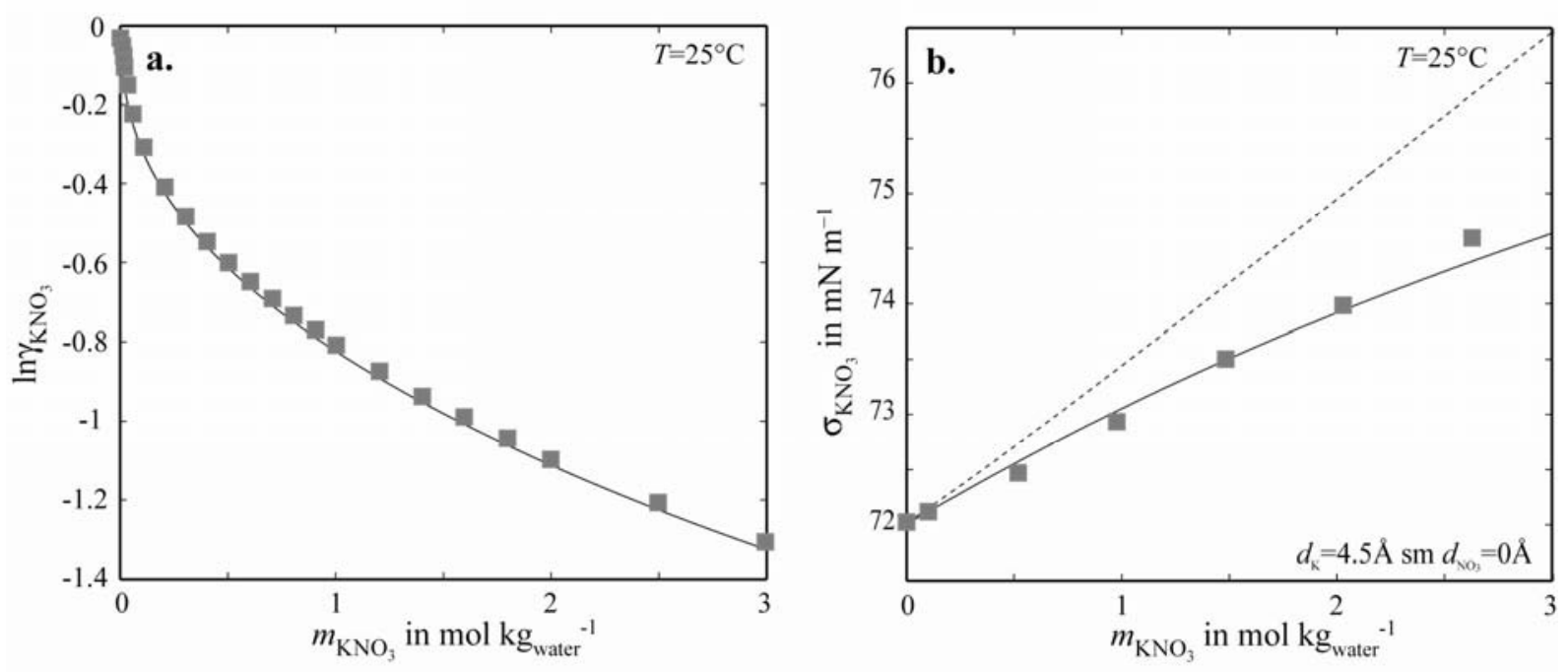

Figure 12. The surface tension (a) and mean activity coefficient (b) of an aqueous $\mathrm{KNO}_{3}$ solution versus its molality in the bulk water. 

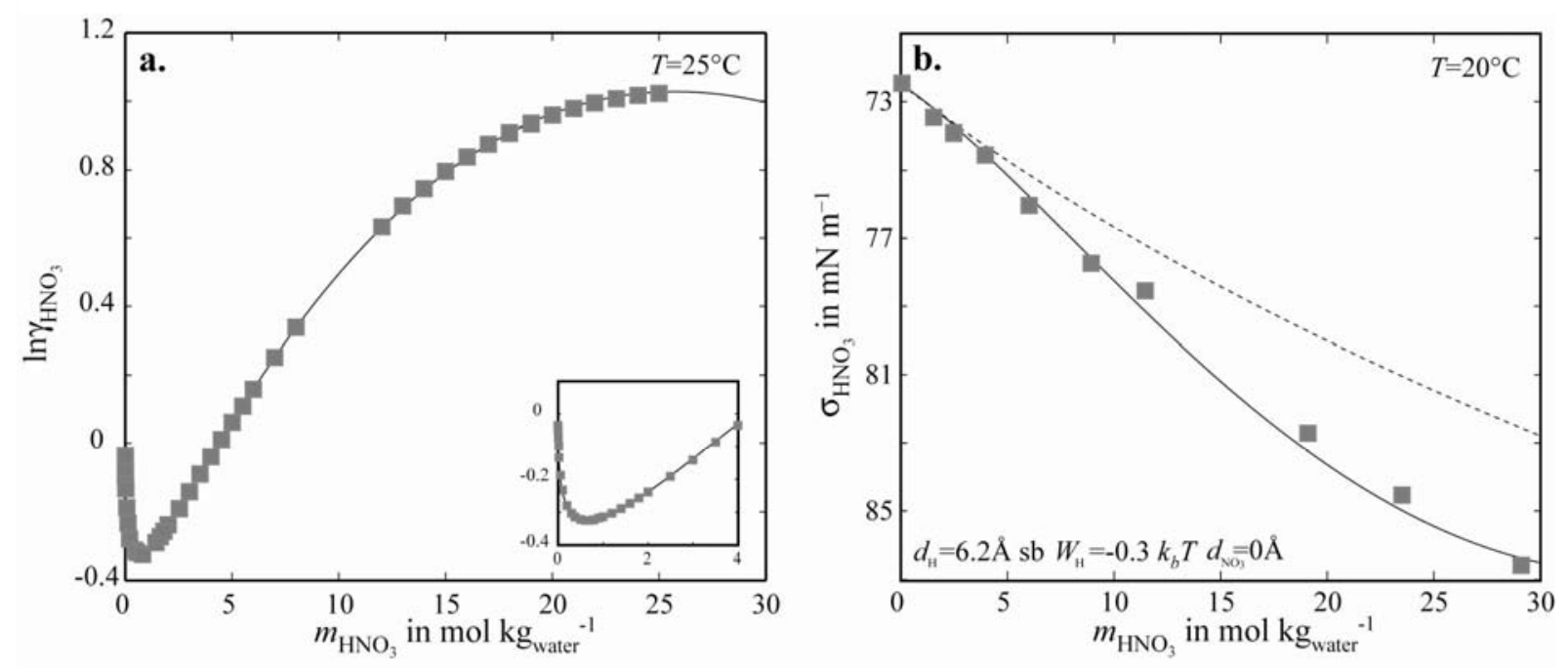

Figure 13. The surface tension (a) and mean activity coefficient (b) of an aqueous $\mathrm{HNO}_{3}$ solution versus its molality in the bulk water (sm: structure-making; sb: structure-breaking). 